صحَت خوشهبندى نهايى

صديقه وحيدى فردوسى و حسين امير خانى"

كروه مهندسى كامييوتر و فناورى اطلاعات، دانشخاه قمه، قمه ايران فيدين

با توجه به ماهيت بدون ناظر مسائل خوشهبندى و تأثير تذارى مؤلفه هاى مختلف از جمله تعداد خواد خوشهها، معيار فاصله و الكوريتم انتخابى،

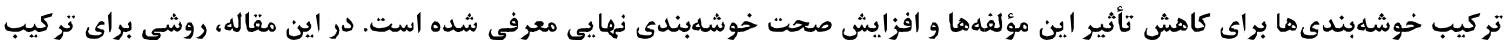

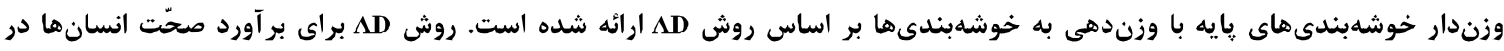

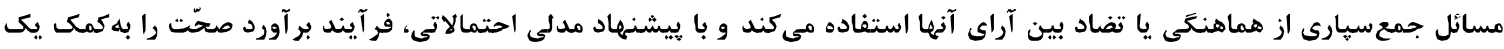

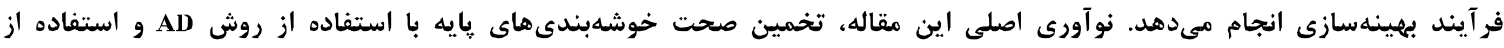

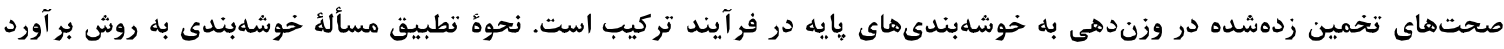

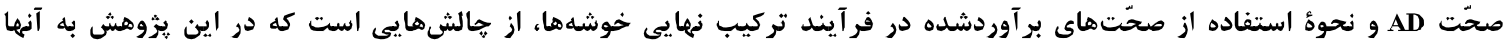

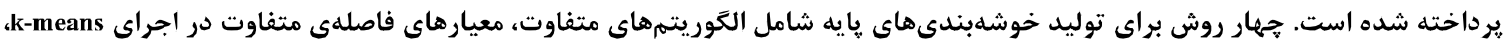

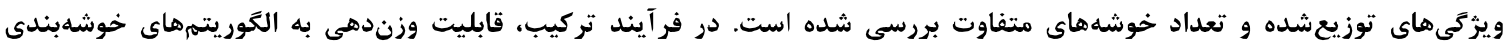

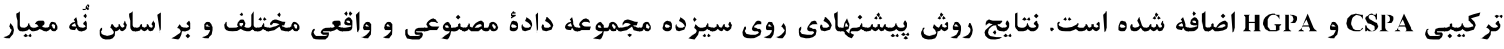

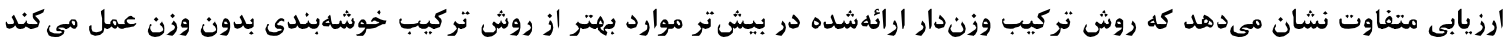

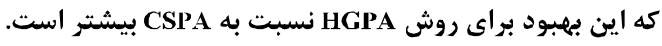

وازَّان كليدى: خوشهبندى تركيبى وزندار، يادَّيرى بدون نظارت، AD CSPA،HGPA.

\title{
Weighted Ensemble Clustering for Increasing the Accuracy of the Final Clustering
}

\author{
Sedigheh Vahidi Ferdosi \& Hossein Amirkhani* \\ Computer Engineering and Information Technology, University of Qom, Qom, Iran
}

\begin{abstract}
Clustering algorithms are highly dependent on different factors such as the number of clusters, the specific clustering algorithm, and the used distance measure. Inspired from ensemble classification, one approach to reduce the effect of these factors on the final clustering is ensemble clustering. Since weighting the base classifiers has been a successful idea in ensemble classification, in this paper we propose a method to use weighting in the ensemble clustering problem. The accuracies of base clusterings are estimated using an algorithm from crowdsourcing literature called agreement/disagreement method (AD). This method exploits the agreements or disagreements between different labelers for estimating their accuracies. It assumes different labelers have labeled a set of samples, so each two persons have an agreement ratio in their labeled samples. Under some independence assumptions, there is a closed-form formula for the agreement ratio between two labelers based on their accuracies. The AD method estimates the labelers' accuracies by

* Corresponding author

* تويسندة عهدهدار مكاتبات
\end{abstract}


minimizing the difference between the parametric agreement ratio from the closed-form formula and the agreement ratio from the labels provided by labelers. To adapt the AD method to the clustering problem, an agreement between two clusterings are defined as having the same opinion about a pair of samples. This agreement can be as either being in the same cluster or being in different clusters. In other words, if two clusterings agree that two samples should be in the same or different clusters, this is considered as an agreement. Then, an optimization problem is solved to obtain the base clusterings' accuracies such that the difference between their available agreement ratios and the expected agreements based on their accuracies is minimized. To generate the base clusterings, we use four different settings including different clustering algorithms, different distance measures, distributed features, and different number of clusters. The used clustering algorithms are mean shift, k-means, mini-batch k-means, affinity propagation, DBSCAN, spectral, BIRCH, and agglomerative clustering with average and ward metrics. For distance measures, we use correlation, city block, cosine, and Euclidean measures. In distributed features setting, the k-means algorithm is performed for $\mathbf{4 0} \%, \mathbf{5 0} \%, \ldots$, and $100 \%$ of randomly selected features. Finally, for different number of clusters, we run the k-means algorithm by $k$ equals to 2 and also $50 \%, 75 \%, 100 \%, 150 \%$, and $200 \%$ of true number of clusters. We add the estimated weights by the AD algorithm to two famous ensemble clustering methods, i.e., Cluster-based Similarity Partitioning Algorithm (CSPA) and Hyper Graph Partitioning Algorithm (HGPA). In CSPA, the similarity matrix is computed by taking a weighted average of the opinions of different clusterings. In HGPA, we propose to weight the hyperedges by different values such as the estimated clustering accuracies, size of clusters, and the silhouette of clusterings. The experiments are performed on 13 real and artificial datasets. The reported evaluation measures include adjusted rand index, Fowlkes-Mallows, mutual index, adjusted mutual index, normalized mutual index, homogeneity, completeness, v-measure, and purity. The results show that in the majority of cases, the proposed weighted-based method outperforms the unweighted ensemble clustering. In addition, the weighting is more effective in improving the HGPA algorithm than CSPA. For different weighting methods proposed for HGPA algorithm, the best average results are obtained when we use the accuracies estimated by the AD method to weight the hyperedges, and the worst results are obtained when using the normalized silhouette measure for weighting. Finally, among different methods for generating base clusterings, the best results in weighted HGPA are obtained when we use different clustering algorithms to come up with different base clusterings.

Keywords: Weighted Ensemble Clustering, Unsupervised Learning, HGPA, CSPA, AD

$$
\begin{aligned}
& \text { مسايلى كه مىتوان به آن اشاره كرد، انتخاب الگوريتم } \\
& \text { خوشهبندى مناسب از ميان روشهاى متفاوت است كه معيار } \\
& \text { ارزيابى يكتايى براى تمايزدادن بين آنها وجود ندارد. } \\
& \text { همجنين نبود معيار سنجش استانداردى براى نتئ نتايج } \\
& \text { خوشهبندى موجب شده بدون هيج دانش قبلى در مورد } \\
& \text { بهترين روش، هر نتيجهاى معقول به نظر برسد [2]. }
\end{aligned}
$$

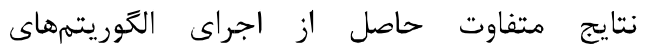

$$
\begin{aligned}
& \text { خوشهبندى مختلف بر روى مجموعة يكسانى از دادهها، }
\end{aligned}
$$

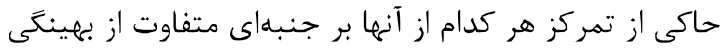

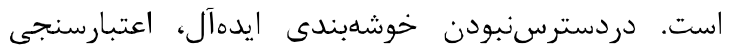

$$
\begin{aligned}
& \text { خوشهبندىها را مشكل ساخته است. علاوهبراين بسيارى از } \\
& \text { الكوريتمها نيازمند تنظيهم يارامترهاى ورودى از جانب كاربر } \\
& \text { هستند كه اين مسأله كنترل كيفيت خوشهبندى را دشوار } \\
& \text { مىسازد. ابعاد بالاى داده نيز از مواردى است كه عملكرد }
\end{aligned}
$$

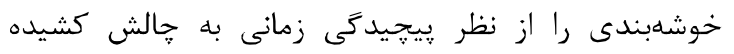

$$
\begin{aligned}
& \text { از آنجايى كه يزوهشهاى انجامشده در زمينه } \\
& \text { دستهبندى تركيبى نمايانگر بهببود نتايج بوده } \\
& \text { منطقى است كه اين روش در خوشابندى نيز مورد بررسى }
\end{aligned}
$$

$$
\begin{aligned}
& \text { - } 1 \\
& \text { خوشهبندى' به فرآيندى كفته مى مود كه در آن مجموعهاى }
\end{aligned}
$$

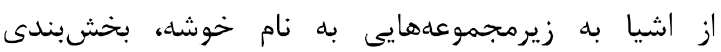

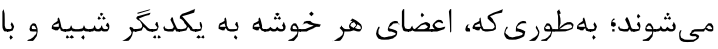

$$
\begin{aligned}
& \text { اعضاى ديگر خوشهها متفاوتاند. ويزگى متمايزكنيدة تحليل } \\
& \text { خوشه نسبت به دستهبندى ؟َ گروهبندى بدون نظارت دادهها } \\
& \text { است. اين فرآيند سودمند مىتواند موجب يافتن زروهها و } \\
& \text { الخوهاى ناشناختهاى در دادهها شود [1]. }
\end{aligned}
$$

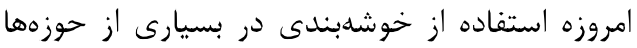

$$
\begin{aligned}
& \text { همجون دادهكاوى، يادكيرى ماشين، جستجوى وب، بازيابى }
\end{aligned}
$$

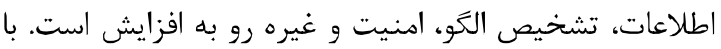

$$
\begin{aligned}
& \text { وجود حجم بالا و گونههاى مختلفى از داده و دادههايى با } \\
& \text { ابعاد بالا تلاشهاى بسيارى براى يافتن روشهاى بالى كارآمد } \\
& \text { انجام شده است. } \\
& \text { اگرجه روشهاى خوشلبندى براى خلاصهسازى و و } \\
& \text { فهم حجم انبوه دادها بسيار مناسب هستند، اما همواره } \\
& \text { يزوهش }
\end{aligned}
$$

${ }^{1}$ clustcring

${ }^{2}$ classification 
خوشهها، از جالشهايى است كه در اين يزوهش به آنها

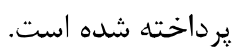

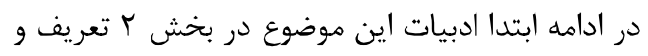

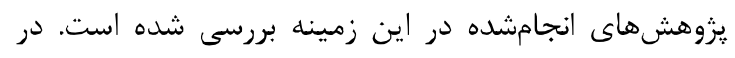

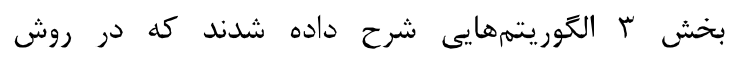

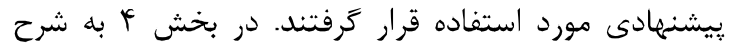

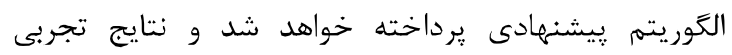

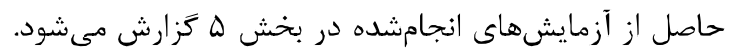

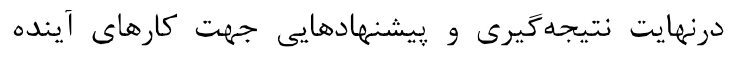
بيان شده است.

\section{r- ادبيات يزوهش و مرور كارهاى ييشين}

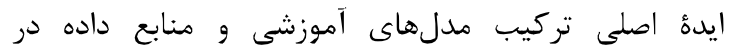

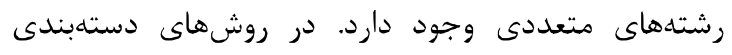

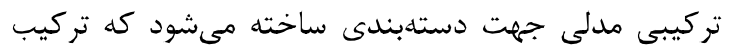

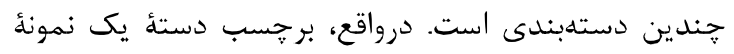
جديد براساس تجميع آراى دستهبندىهاى دراى اوليه تعيين

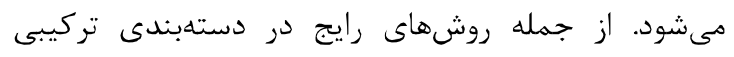

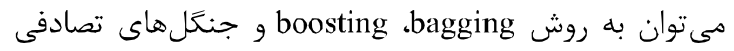

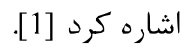

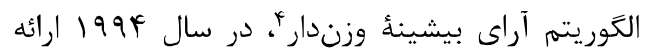

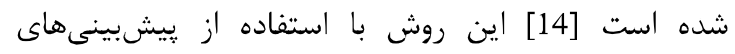

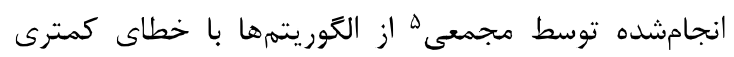

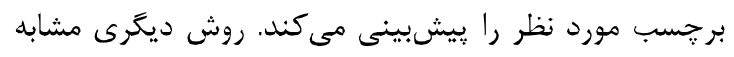

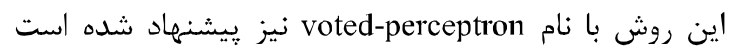

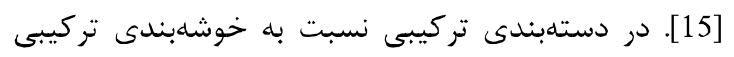

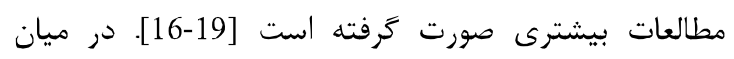

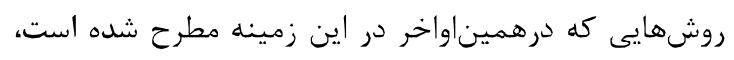

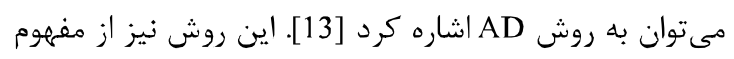

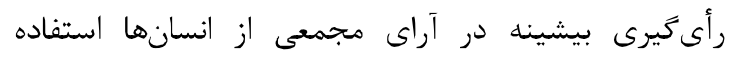

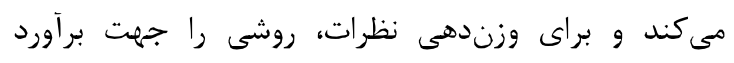

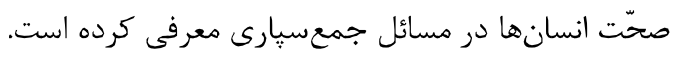

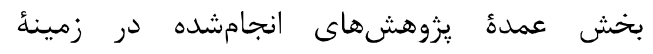

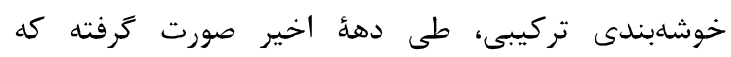

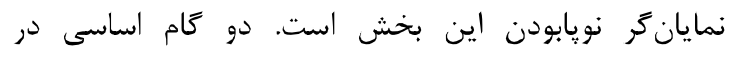

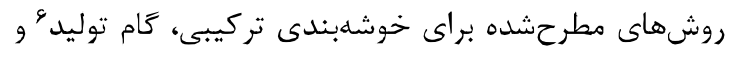

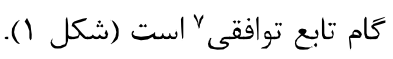

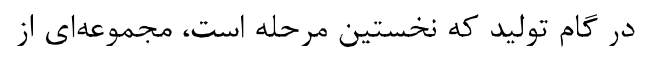

${ }^{4}$ weighted majority algorithm

${ }^{5}$ ensemble

${ }_{7}^{6}$ generation

7 consensus function
قرار بكيرد. خوشهبندى تركيبى شامل تجميع جندين افراز

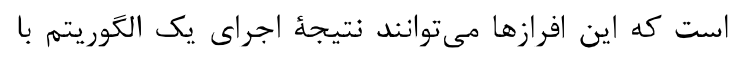

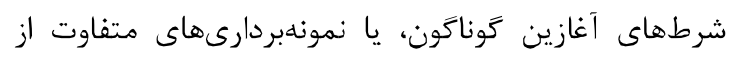

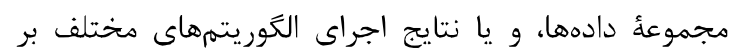
روى مجموعه دادة يكسان باشند. روشهاى خوشهبندى تركيبى مىتوانند راهحلهاى باش

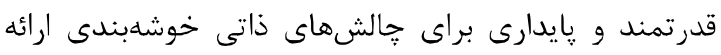

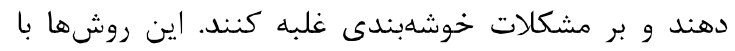

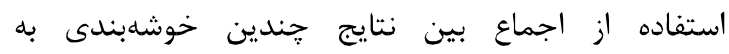

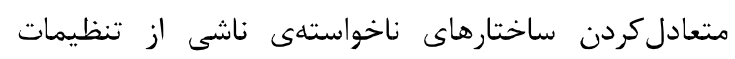

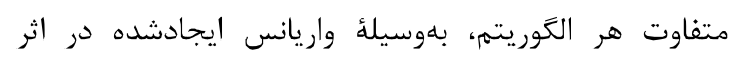

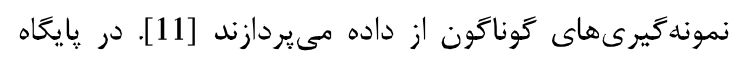

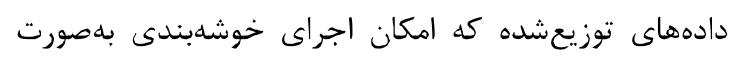

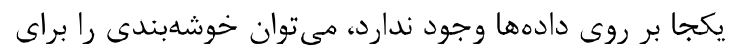

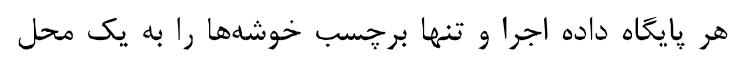

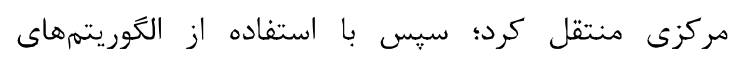

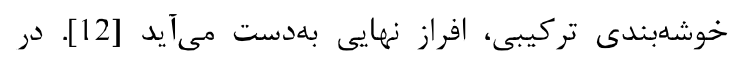

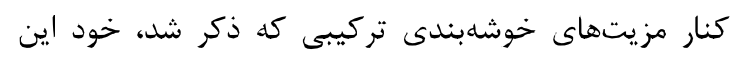

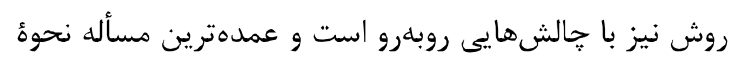

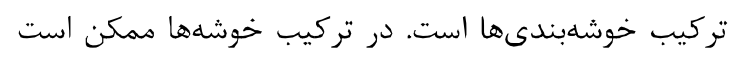

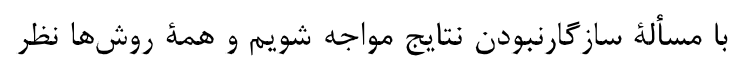

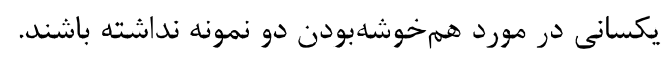

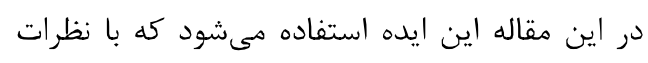

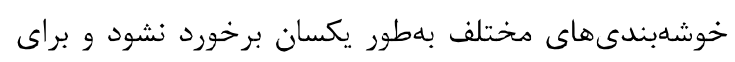

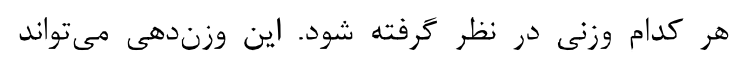

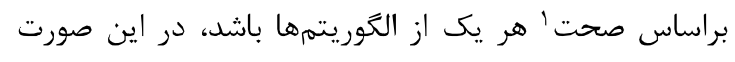

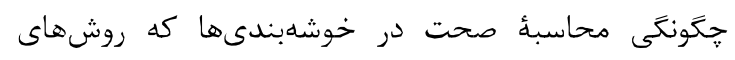

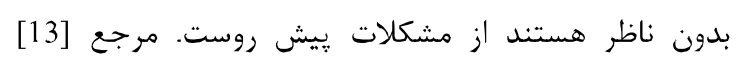

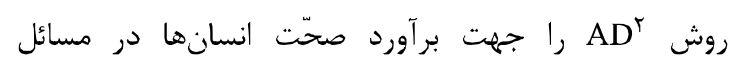

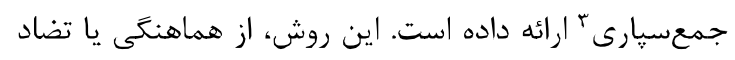

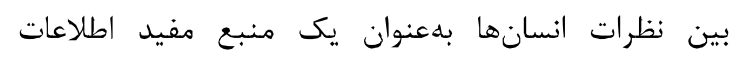

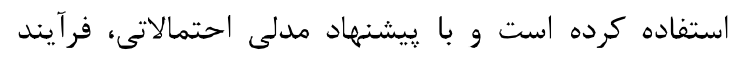

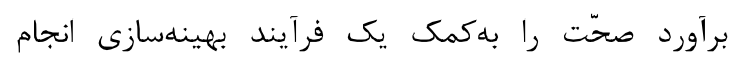

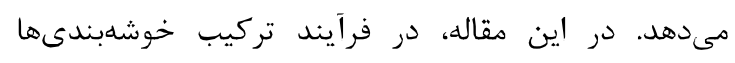

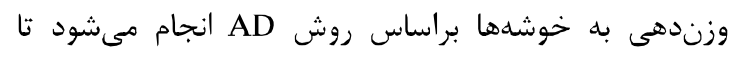

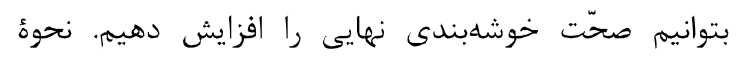

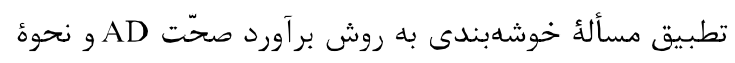
استفاده از صحّتهاى برآورشدهد در فر برآيند تركيب نهائي

\footnotetext{
1 accuracy

2 agreement/disagreement

3 crowdsourcing
} 


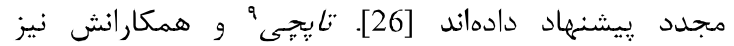
هارجوبى يكيار ״ه براى ايجاد افرازهاى متعدد ارائه دادهاند

عليز/ده و همكاران براى خوشابندى تركيبى روشى

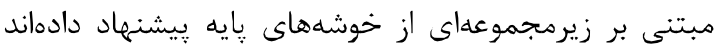

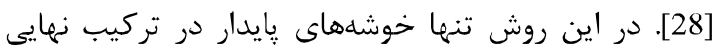

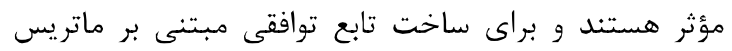

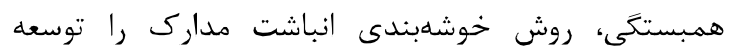
دادهاند. مرجع [29] با تعبيئ خوشهبندى در فضاهاى بردارى،

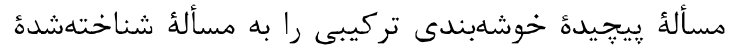

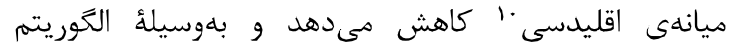
Weiszfeld خوشهبندى مسطح تمركز دارند؛ اما ميرز/يى در رساله خود به دعرفى تركيب خوشهبندىهاى سلسلهمراتبى يرداخته

در ميان يزوهشهايى كه در زمينهأ خوشابندى تركيبى وزندار صورت گرفته است، ميىتوان به رئ روش

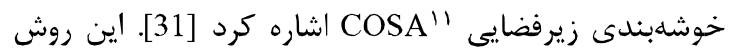
به ازاى هر داده يكى بردار وزن براى ويزّكى ها تعريف مى كنى

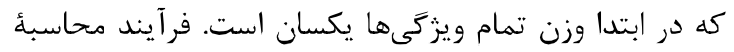
فواصل دادهها با توجه به وزن ويزگىها، اجراى باروزرسانى وزن ويزكى ها تا جايى تكرار مىشود كه كمينه

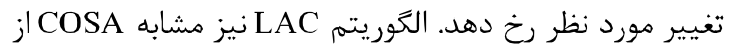

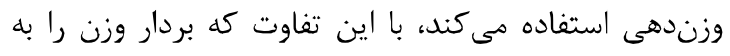
خوشdها اختصاص مى دهد [32]. التوريتهم افرازبندى مشابهت وزندار (WSPA) rا براى

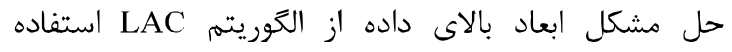
مى كند و افراز توافقى با افرازبندى كرافى بهدست ميى آيد كه از ماتريس شباهتى مبتنى بر بردار احتمال نسبت دادهده

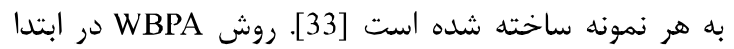

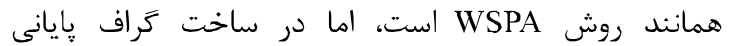
همانطور كه از نام آن مشخص است، يك كراف دوبخشى از نمونهها و خوشهها مىسازد [33]. رويكرد در خوشهبندى زيرفضايى با استفاده از خوشهبندى

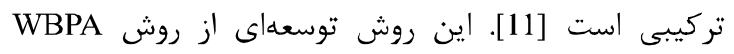
است كه علاوهبر افرازبندى نهايى، بردار وزن ويزگىها براى

هر خوشه نيز ارائه مىشود.

\footnotetext{
${ }^{9}$ Topchy

${ }^{10}$ euclidean median

${ }^{11}$ clustering objects on subsets of attributes

12 weighted similarity partitioning algorithm

${ }^{13}$ weighted subspace bipartite partitioning algorithm
}

خوشهبندىها از مجموعة داده توليد مىشوند؛ سيس در مرحلة دوم بايد نتايج حاصل از خوشهبندى نهاى يايه بلهوسيلة

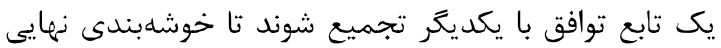
بلمدست آيد.

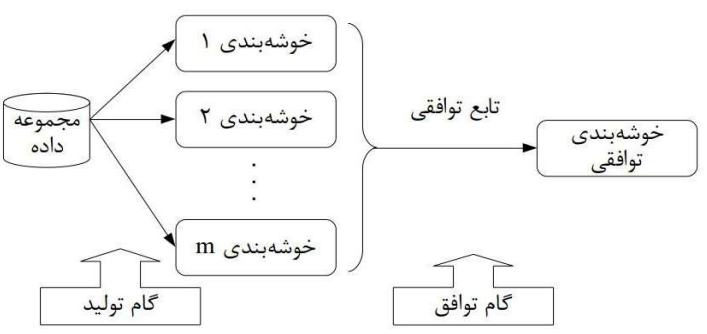

(شكل - |): نمودار فر آيند كلى خوشهبندى تركيبى |2]

(Figure-1): The general process of ensemble clustering [2]

استرل و كاثل' جزء نخستين كسانى بودند كه

تركيب را در خوشهبندى مورد يزوهش قرار دادند [12]. آنها

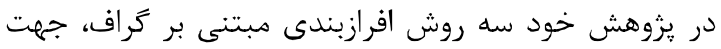

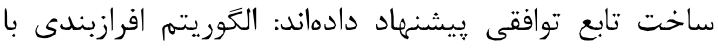

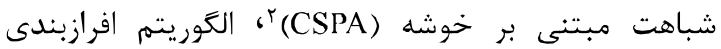

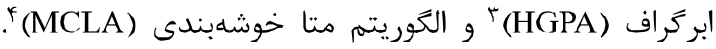
در اين روشها ابتدا مجموعة خوشهبندىهاى يايه بهصورت يك ابركراف مدل و محاسبات ديخر با استفاده از اين ابرگراف

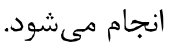

حدود يك سال بعد فرد و جينه به برد برسى ايده جمعآورى شواهد براى تركيب نتايج جندين خوشهبندى بعد يرداختند [20]. آنها براى ساخت تابع توافق، افرازهاى اشيا رائ

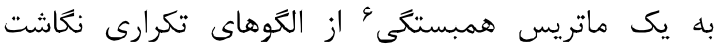

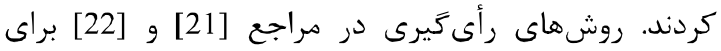
ساختن تابع توافقى بهعنوان جايگزينى براى ماتريس

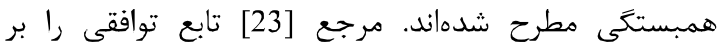

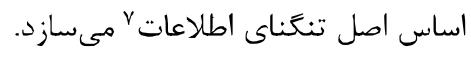

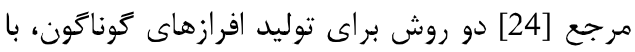

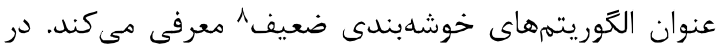

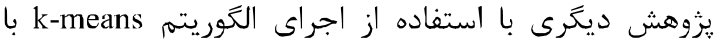

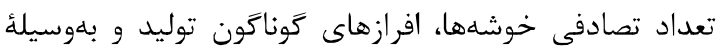
ماتريس تطابق بين تمام جفت اشيا افرازها تركيب مىشوند [25]. مينايى و همكارانش روشى مبتنى بر نمونهبردارى

\footnotetext{
${ }^{1}$ Strehl and Ghosh

2 cluster-based similarity partitioning algorithm

${ }^{3}$ hypergraph partitioning algorithm

${ }^{4}$ meta-clustering algorithm

${ }^{5}$ Fred and Jain

${ }^{6}$ co-association matrix

7 information bottleneck principle

${ }^{8}$ weak clustering algorithms
} 
تركيب كرده و روشى با عنوان K-MWO ارائه داده است. اين

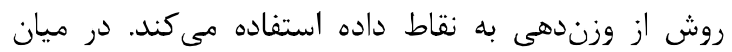
يروهشهاى داخلى نيز يروين در رساله خود روش جديدى إنى

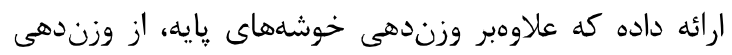
ويزگى هاى هر خوشه نيز استفاده كرده است [42].

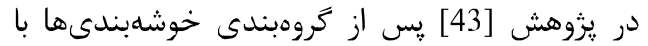
استفاده از معيارهاى شباهت، با كيفيتترين خوشهبندى از

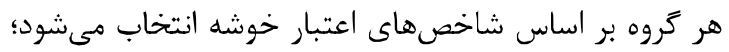

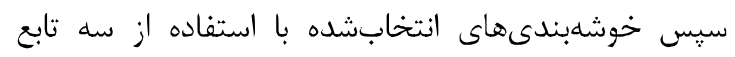

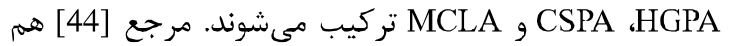
از توافق/عدم توافق خوشهبندىها براى سنجش اعتبار آنها

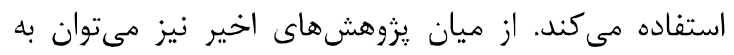
مراجع [48-48] اشاره كرد. با توجه به يزوهشهاى انجامشده، برآورد صحّت خوشهبندىها با توجه به ماهيت بدون ناظر آنها يكى از براز

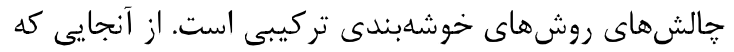
در روش AD وزندهى صرفاً با استفاده از آراى دستدبندها انجام مىشود، بررسى اين روش در زمينهُ خوشهبندى

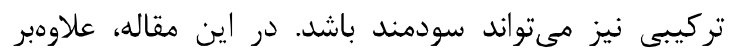

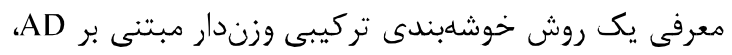

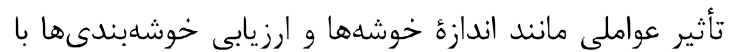

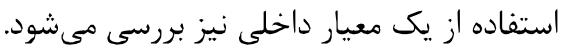

\section{ب - الكَوريتمهاى مورد استفاده \\ ا-r- الكَوريتم CSPA}

الكَوريتم CSPA يكى از روشهاى خوشهبندى تركيبى مبتنى بر كراف است كه در مرجع [12] ارائه شده است. اكر r خوشهبندى، n داده و k خوشه داشته باشيه، براى بردار برجسب هر يك از خوشهبندىها

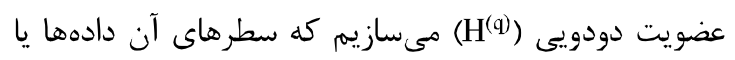
همان رئوس ابركراف و ستونها، خوشهها يا ابريالها هستند.

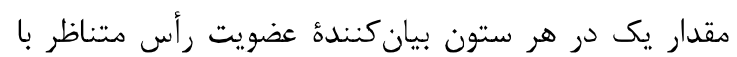

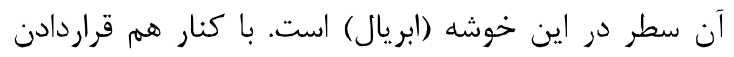
ماتريس تمام خوشهبندىهاى پايه، بلوكى از إن ماتريسها

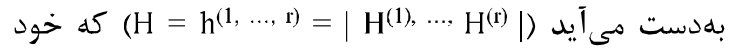
ماتريس مجاورت يك ابركراف با n رأس و

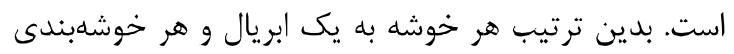

$$
\text { به يك ابركراف نكاشت مىشود. }
$$

در روش WKF كام ارزيابى كيفيت افرازبندىها

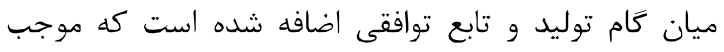

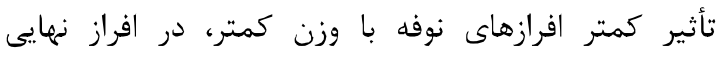

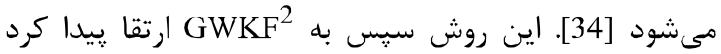

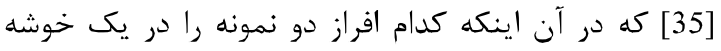

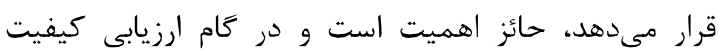
افرازبندىها ديكر احتياجى به دسترسى به دادههاى اصلى إنى

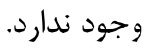

در زمينهُ وزندهى به خوشهبندىها مرجع [36] ثابت

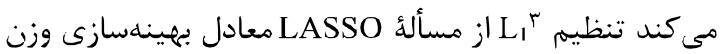

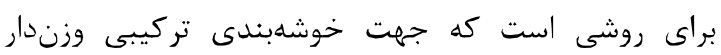
بيشنهاد مىدهد. كولو و و همكارانش سه طرح براى تجميع

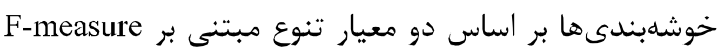

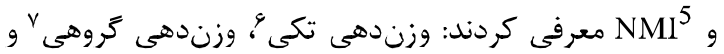

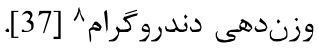

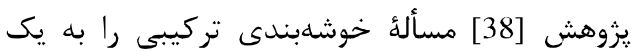

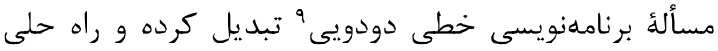

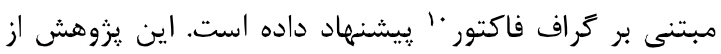

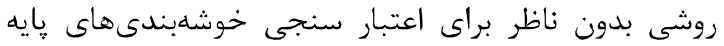

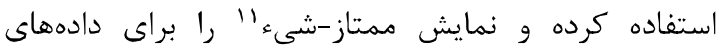
حاصل تجميع بيشنهاد داده است.

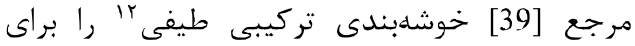

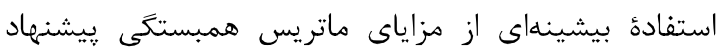

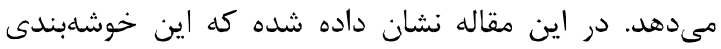

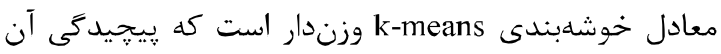

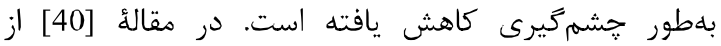
وزندهى به اشيا در فرآيند تجميع خوشهبندي بانه است استفاده شده

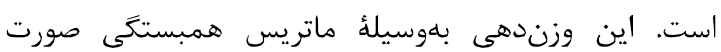

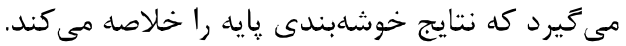

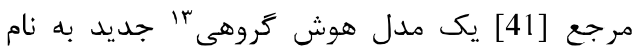

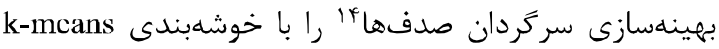

${ }^{1}$ weighted cluster ensemble using a kernel consensus function

${ }^{2}$ generalized WKF

${ }^{3}$ regularization

${ }^{4}$ Gullo

${ }^{5}$ normalized mutual information

${ }^{6}$ single weighting

${ }^{7}$ group weighting

8 dendrogram weighting

${ }^{9}$ binary linear programming

${ }^{10}$ factor graph

${ }^{11}$ super-object

${ }^{12}$ spectral ensemble clustering

${ }^{13}$ swarm intelligence model

${ }^{14}$ mussels wandering optimization 
برآوردشده جهت برآورد برجسبهاى درست.

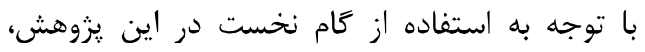

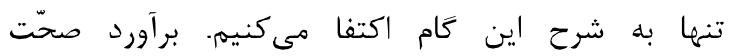

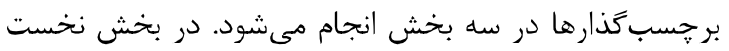

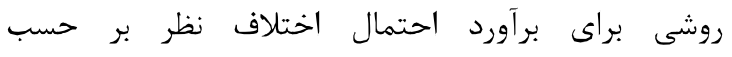

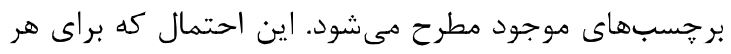
جفت برجسبكذار محاسبه و

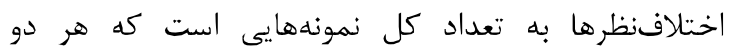
برجسب گذذار در مورد آن نظر دادهاند.

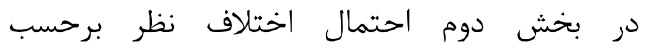

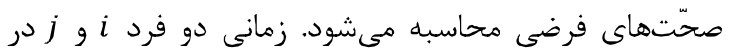

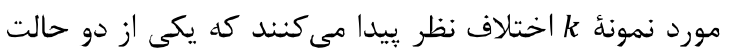
زير رخ دهد:

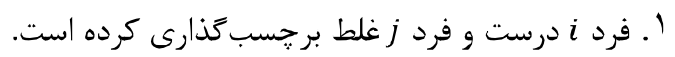

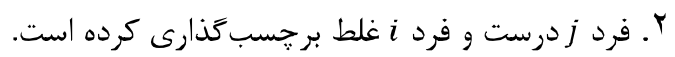
حالت نخست را

$P\left(O_{k}^{i} \neq O_{k}^{j}\right)=P\left(E_{1}\right)+P\left(E_{2}\right)=$

$\mathrm{P}\left(\mathrm{O}_{\mathrm{k}}^{\mathrm{i}}=\mathrm{y}_{\mathrm{k}}, \mathrm{O}_{\mathrm{k}}^{\mathrm{i}}=1-\mathrm{y}_{\mathrm{k}}\right)+$

$\mathrm{P}\left(\mathrm{O}_{\mathrm{k}}^{\mathrm{i}}=1-\mathrm{y}_{\mathrm{k}}, \mathrm{O}_{\mathrm{k}}^{\mathrm{j}}=\mathrm{y}_{\mathrm{k}}\right)$

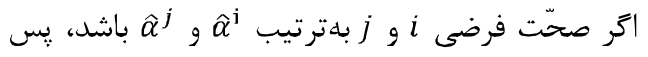

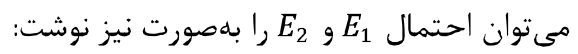

$P\left(O_{k}^{i}=y_{k}, O_{k}^{j}=1-y_{k}\right)=$

$P\left(O_{k}^{i}=y_{k}\right) P\left(O_{k}^{j}=1-y_{k}\right)=\hat{\alpha}^{i}\left(1-\hat{\alpha}^{j}\right)$

$P\left(O_{k}^{i}=1-y_{k}, O_{k}^{j}=y_{k}\right)=$

$P\left(O_{k}^{i}=1-y_{k}\right) P\left(O_{k}^{j}=y_{k}\right)=\left(1-\hat{\alpha}^{i}\right) \hat{\alpha}^{j}$

در نتيجه معادله (T) به اين ترتيب سادهسازى مىشود:

$P\left(O_{k}^{i} \neq O_{k}^{j}\right)=\hat{\alpha}^{i}+\hat{\alpha}^{j}-2 \hat{\alpha}^{i} \hat{\alpha}^{j}$

ماتريس اين احتمالات

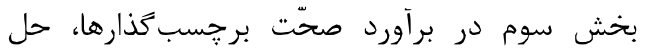

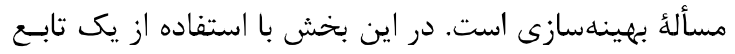
بهينهسازى اختلاف بيـن

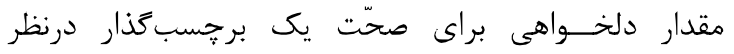

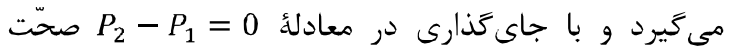

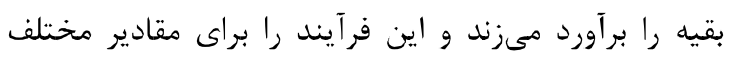

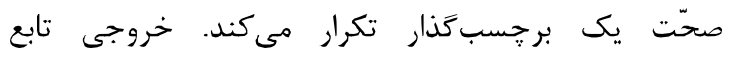

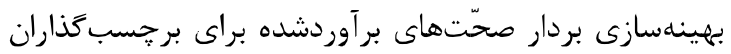

بنابراين، اكر شباهت دو شىء را كه در خوشهٔ يكسان هستند يك و غير اين صورت صفر تعريف كنيم، مىتوانيم

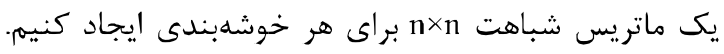
در اين صورت با محاسبة ميانكين بين درايههاى متناظر ماتريس هر خوشهبندى، مىتوان ماتريس شباهتى تعريف كرد كه از طريق معادلة (1) قابل محاسبه است. $S=\frac{1}{r} H H^{t}$

رئوس كراف شباهت حاصلشده از اين ماتريس با

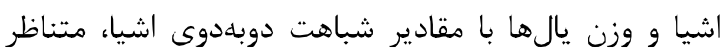

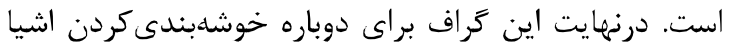

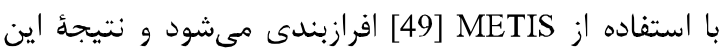
افراز، تجميع خوشهبندى هاى مختلف را بهدست مى إنهد.

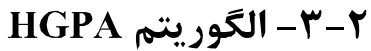

اين الكَوريتم نيز جزء سه روش افرازبندى مبتنى بر كراف

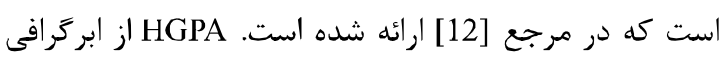
كه مشابه ابركراف الكوريته

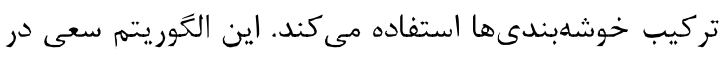

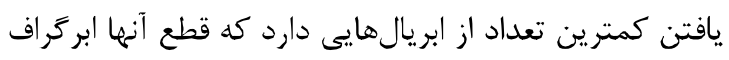

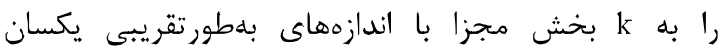

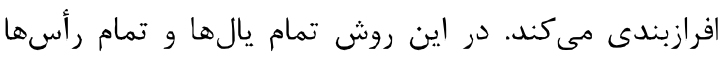

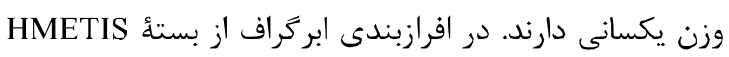

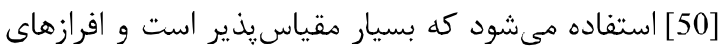
با كيفيت بالايى توليد مى كند.

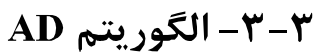

اين الثوريتم جهت برآورد صحّت انسانها در مسائل

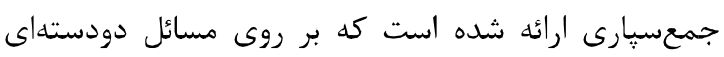

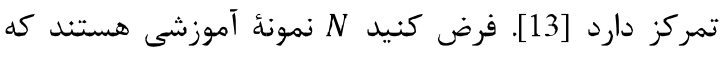
برجسبهاى درست آنها

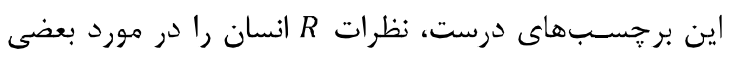

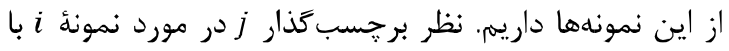

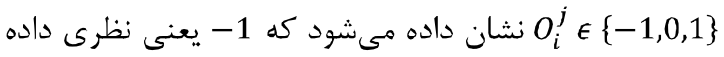

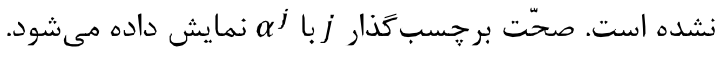

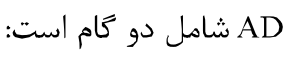

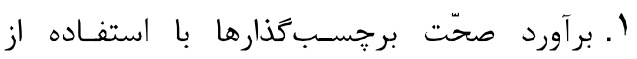

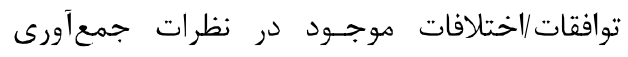
شلهـ Y. يكى كردن نظرات با استفاده از صحّتهاى 
انتقال ميانخين'، خوشابندى تجميعى ب با دو معيار ward و 'DBSCAN ،Mini-batch k-means ‘k-means ‘average BIRCH , Spectral 'Affinity Propagation جداكَانه بر روى دادهها اجرا مىشوند؛ سيس نتايج اين

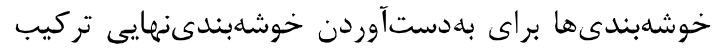
مىشوند.

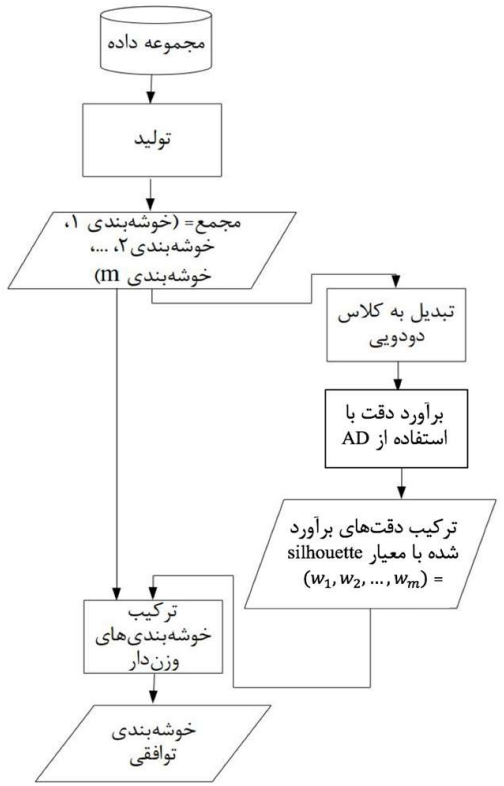

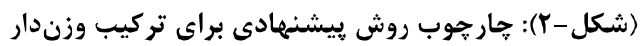

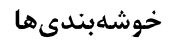

(Figure-2): The proposed method for weighted ensemble clustering

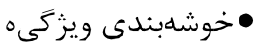

•اى توزيعشده (FDC

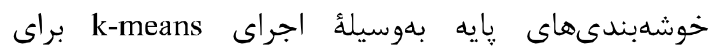

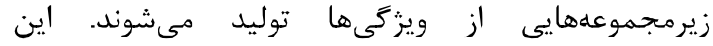

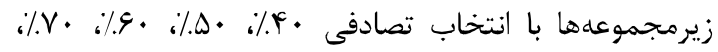

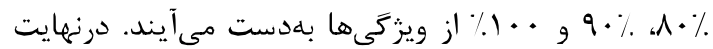
هفت خوشهبندى ايجادشده تركيب و نتيجئ توافقى حاصل

$$
\text { مىشود. }
$$

•استفاده از معيارهاى فاصلة متفاوت در اجراى k-means:

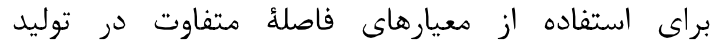

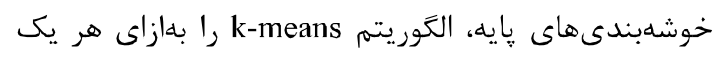

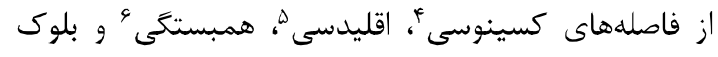

\section{${ }^{1}$ mean shift}

2 agglomerative clustering

${ }^{3}$ feature-distributed clustering

${ }^{4}$ cosine

${ }^{5}$ cuclidean

${ }^{6}$ correlation
با توجه به معادله (ه) براى برآورد صحّت برجسب گذارها، اين مسأله دو نقطهُ بهينه دارن:

$\hat{\alpha}^{i}+\hat{\alpha}^{j}-2 \hat{\alpha}^{i} \hat{\alpha}^{j}=$

$\left(1-\hat{\alpha}^{i}\right)+\left(1-\hat{\alpha}^{j}\right)-2\left(1-\hat{\alpha}^{i}\right)\left(1-\hat{\alpha}^{j}\right)$

بنابراين، با جايگزين كردن بردار (1- $\left.\hat{\alpha}^{1}, \ldots, 1-\hat{\alpha}^{R}\right)$

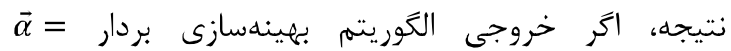
$1-\vec{\alpha}=\left(1-\hat{\alpha}^{1}, \ldots, 1-\hat{\alpha}^{R}\right)$ باشد، بردائ $\left.1 \hat{\alpha}^{1}, \ldots, \hat{\alpha}^{R}\right)$

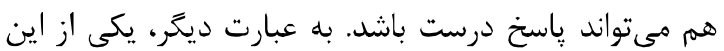
نقطهها بهينهُ درست و ديخرى غلط است است. براى مسأله بحثشده در اين مقاله، روشى جهت تشخيص بهينه درست طراحى و بررسى شده است كه در بخش بعد معرفى خواهد

\section{P}

ايدهُ مطرحشده در روش ييشنهادى، استفاده از صحّتهاى خوشهبندىهاى يايه بهعنوان وزن هر يك از آنها در فرآيند

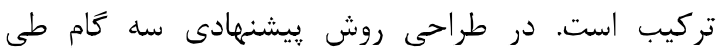

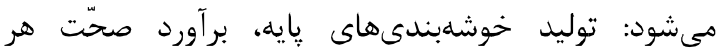
خوشهبندى با استفاده از روش AD و معيار silhouette و تركيب خوشهبندىهاى يايه مبتنى بر وزنهاى برآوردشدها. شكل (r) اين مراحل را به تصوير كشيده است.

\section{|F- F- Fام نخست: توليد خوشهبندىهاى يايه}

در رام نخست روشهاى متفاوتى براى توليد خوشهبندىهاى يايه مورد بررسى قرار داده شده است. با

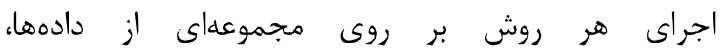
خوشهبندىهاى اوليه بلدست مى آيند. در ادامه روشهاى روى روسي مورد استفاده در آزمايشها براى توليد خوشهبندىهاى بايه

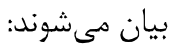
• اجراى k-means با kاى متفاوت: در اين روش، تركيب بر روى خوشابندىهاى حاصل از اجراى الگوريتم k-means

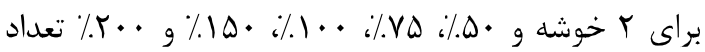
واقعى خوشهها صورت مى كيرد. خوشهبندى توافقى براى تعداد خوشههايى معادل تعداد واقعى بهدست مى آيد. •استفاده از الخَوريتمهاى متفاوت: در اين روش مجموعهاى

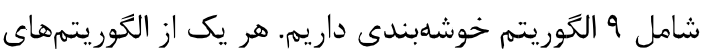


Algorithm 1: Convert ensemble to binary opinions

Parameters: $N$ (number of instances), $R$ (number of clusterings)

Input: Dataset, Ensemble $(R \times N)$

Output: ADinput $\left(R \times N^{2}\right)$

(1) for clusterings in Ensemble do

(2) Index $\leftarrow 0$

(3) for $(\mathrm{i}, \mathrm{j})$ in Dataset $^{2}$ do

(3) for $(i, j)$ in Dataset ${ }^{2}$ do
(4) If clusterings (i) $=$ clusterings (j) then

(5) ADinput (labeler)(index) $\leftarrow 1$

(6) else do

(7) ADinput (labeler)(index) $\leftarrow 0$

(8) Index $\leftarrow$ Index +1

(9) end for

(10)end for

(شكل - Y): الكَوريتم تبديل مجموعهاى از خوشهبندىها به نظرات

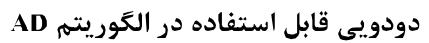

(Figure-3): Converting an ensemble of clusterings to binary opinions which can be used in $\Lambda D$ algorithm

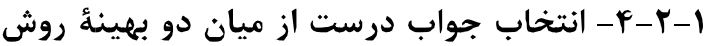

AD

براى تشخيص بهينه درست از غلط آخرين نمونه موجود در

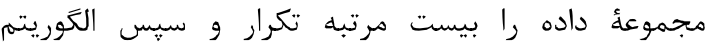

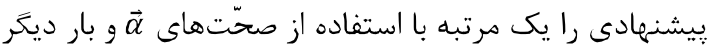
با استفاده از

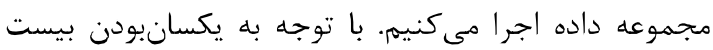

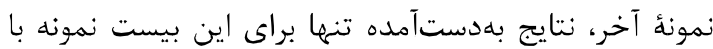

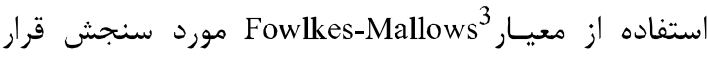
مى تيرد.

براى تمام مجموعهدادهها، روشهاى توليد

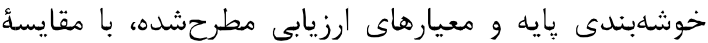

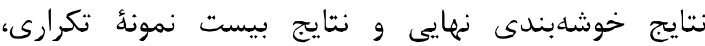
مشاهده شد هر يك از وزندهىها كه براى بيست نمونه تكرارى بهتر عمل كرده، در خوشابندى نهايى نيز نئ عملكرد Fowlkes- بهترى داشته است. بنابراين بيشترين مقدار معيار Mallows براى اين بيست نمونه نشاندهنده استفاده از

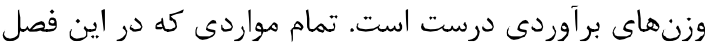

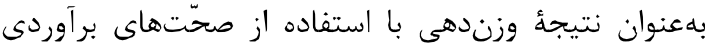

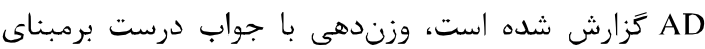

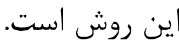

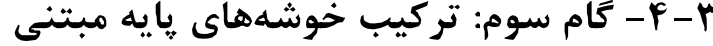 بر وزنهاى بر آور دشده}

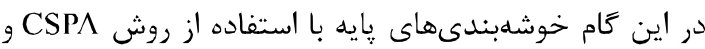
HGPA آنها را شرح مىدهيم. در روش CSPA وزندار از صحّتهاى برآوردشده توسط AD بهعنوان وزن خوشابندىها استفاده مىشود. در روش HGPA وزندار، براى وزن ابريالها در

${ }^{3}$ http://scikit-learn.org/stable/modules/ clustering.html\#fowlkes-mallows-scores
شهرى' دو بار بلطور مستقل اجرا مىكنيم (جدول (1).

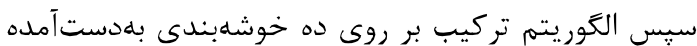

اجرا مىشود. مستند جزئيات ييادهسازىهاى اين معيارها

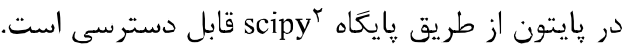

(جدول -1): معيار هاى فاصله مورد استفاده :-19اه

(Table-1): The used distance metrics

\begin{tabular}{|c|c|}
\hline 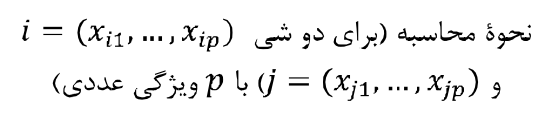 & نام معيار \\
\hline$\sqrt{\left(x_{i 1}-x_{j 1}\right)^{2}+\ldots+\left(x_{i p}-x_{j p}\right)^{2}}$ & اقليدسى [1] \\
\hline$\left|x_{i 1}-x_{j 1}\right|+\ldots+\left|x_{i p}-x_{j p}\right|$ & بلوك شهرى [1] \\
\hline $\begin{array}{l}d(i, j)=1-\frac{i^{T} \cdot j}{\|i\| \cdot\|j\|^{\prime}} \\
\|i\|={\sqrt{x_{i 1}{ }^{2}+\ldots+x_{i p}}}^{2}\end{array}$ & كسينوسى [51] \\
\hline $\begin{array}{l}d(i, j)=1-\frac{(i-\bar{\imath})^{T} \cdot(j-\bar{\jmath})}{\|i-\bar{l}\| .\|j-\bar{j}\|} \\
\bar{\imath}=\frac{x_{i 1}+\ldots+x_{i p}}{p}\end{array}$ & همبستغى [51] \\
\hline
\end{tabular}

Y-F- Fام دوم: برآورد صحت هر خوشهبندى

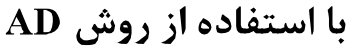

از آنجايى كه روش AD بر روى مسائل دودستهاى كار

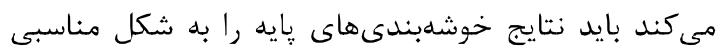

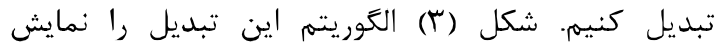

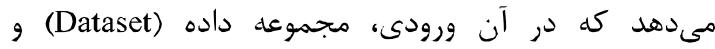
ماتريس خوشهبندىهاى يايه در كام توليد (Ensemble)

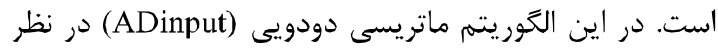

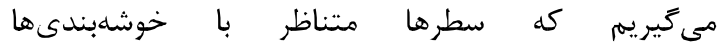
(برجسبكذاران) هستند. ستونها نيز، زوج مرتبهايى

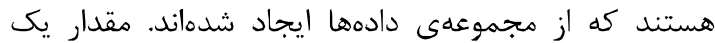
براى يك زوج مرتب (i,j) در سطر k به اين معنى است كه

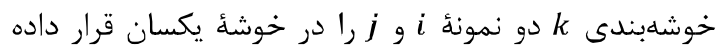

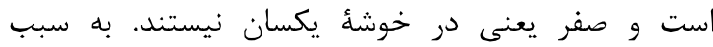

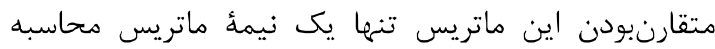

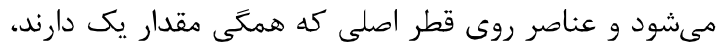

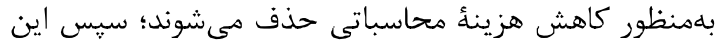

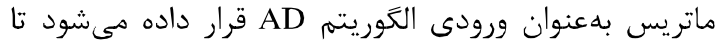

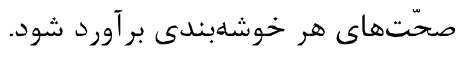

1 city block

${ }^{2}$ http://docs.scipy.org/doc/scipy/reference/ spatial.distance.html 


$$
\begin{aligned}
& \operatorname{score}\left(\lambda^{t}\right)= \\
& \left\{\begin{array}{cc}
w_{1} & \text { if label }\left(x_{i}\right)=\operatorname{label}\left(x_{j}\right) \\
1-w_{l} & \text { otherwise. }
\end{array}\right.
\end{aligned}
$$

به عبارت ديكر اگر خوشهبندى با وزن w دو نمونه را در يك

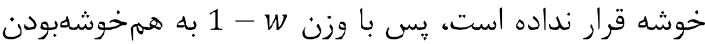

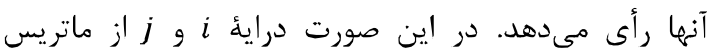
شباهت از معادلأ (A) بهدست مى آيد.

$S(i, j)=\sum_{l=1}^{r} \frac{\operatorname{score}\left(\lambda^{l}\right)}{r}$

براى وزنداركردن HGPA كافى است به جاى يكسان درنظركرفتن وزن ابريالها، وزنهاى هحاسبهشده براى هر خوشهبندى (طبق جدول r) را بهعنوان وزن ابريالهاى معادل آن در ابركراف در نظر بغيريم.

ه- نتايج تجربى

در اين بخش بله بيان نتايج حاصل از آزمايش روش

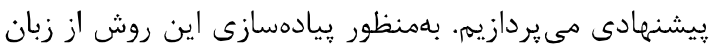

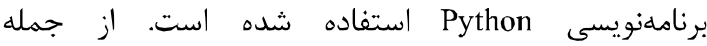
كتابخانههاى مورد استفاده در اين يزوهش مىتوان به

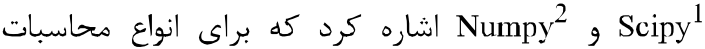
عددى و ههندسى ارائه شدهاند. همجنين مازول يادكيرى

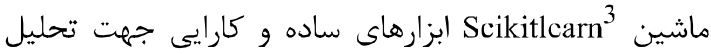

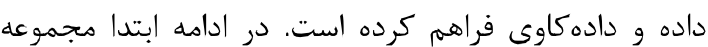
دادههاى مورد بررسى و معيارهاى ارزيابى مورد استفاده بيان مىشوند و سيس به بيان نتايج مىيردازيهم.

\section{1-هـ- مجموعهدادههاى مورد آزمايش}

كارايى الكوريتهم يِيشنهادى در مقايسه با الثوريتمهاى ديخر در خ جندين مجموعلدادهُ واقعى و دستساز بررسى مىشود. مجموعلداده دستساز دادههايى هستند كه توسط استرل و كاش تهيه شدهاند و از طريق (http://strehl.com) قابل دسترسى است. مجموعه دادههاى واقعى مورد استفاده،

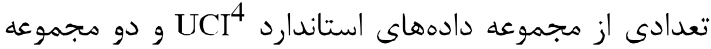

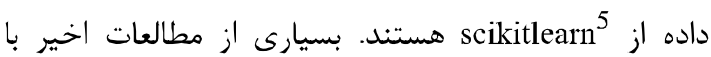

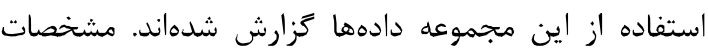
دادهاى مورد آزمايش در جدول (با) ارائه شده است.

\footnotetext{
${ }^{1}$ http://www.scipy.org

${ }^{2}$ http://www.numpy.org

${ }^{3}$ http://www.scikit-learn.org

${ }^{4}$ https://archivc.ics.uci.cdu/ml/datascts.html

${ }^{5}$ http://scikit-learn.org/stable/datasets/\#toy-datasets
}

حالتهاى مختلف تركيب، سه يارامتر صحّت هاى برآوردشده بلوسيلة AD silhouette و اندازه خوشهها بررسى مىشود. جدول (T) انواع وزندهى بهاى مورد آزمايش براى را نشان مى دهد. HGPA

(جدول - Y): شيوههاى مختلف وزندهى ابريالهاى در HGPA (Table-2): Different ways of weighting hyperedges in HGPA

\begin{tabular}{|c|c|}
\hline وزن ابريالها & نماد \\
\hline int $($ accuracy $\times 1000)$ & $w_{1}$ \\
\hline int $($ accuracy $\times 1000) \times$ Vertices & $w_{2}$ \\
\hline $\operatorname{int}($ accuracy $\times 1000) \times \operatorname{int}\left(\frac{\text { Vertices }}{N} \times 1000\right)$ & $w_{3}$ \\
\hline $\operatorname{int}($ silhouette $\times 1000) \times \operatorname{int}\left(\frac{\text { Vertices }}{N} \times 1000\right)$ & $w_{4}$ \\
\hline int $($ silhouette $\times 1000)$ & $w_{5}$ \\
\hline $\operatorname{int}($ accuracy $\times$ silhouette $\times 1000)$ & $w_{6}$ \\
\hline $\begin{array}{c}\operatorname{int}(\text { accuracy } \times \text { silhouette } \times 1000) \times \operatorname{int}\left(\frac{\text { Vertices }}{N}\right. \\
\times 1000)\end{array}$ & $w_{7}$ \\
\hline
\end{tabular}
algorithm

يارامتر accuracy در جدول (r) با جاى جذارى صحّتهاى برآوردشده توسط AD بلهور جداكانه آزمايش

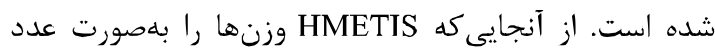
صحيح مىيذيرن، صحّت را كه عددى بين صفر و يك است است آن در هزار ضرب و سيس به عدد صحيح تبديل كردهايهم. يارامتر

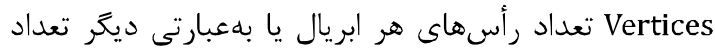

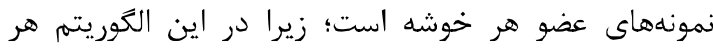
خوشه به يك ابريال نكاشت ميىشود. N تعداد كل نمونهها

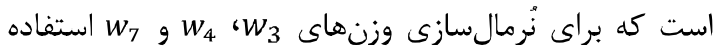

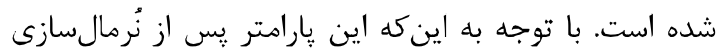

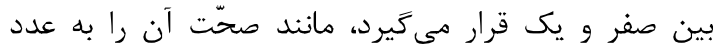
صحيح تبديل مى كنيم. Silhouette يك معيار ارزيابى

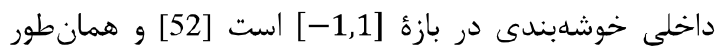
كه بيشتر توضيح داده شد به عدد صحيح تبديل مىشود.

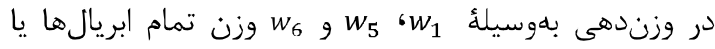
خوشههاى يك خوشهبندى يكسان است؛ زيرا صحّت و معيار براى كل خوشهبندى محاسبه مىشود و براى silhouette خوشههاى داخل خوشهبندى متفاوت نيست.

ו-r-r با اندك تغييرى در CSPA، امكان تركيب وزندار خوشهبندىها را به اين الكوريتم خوشهبندى تركيبى اضافه كردهايم. اكر r خوشهبندى داشته باشيم، براى ساخت ماتريس شباهت، ابتدا براى هر زوج نمونه خوشهبندى (V) محاسبه مى كنيم. 


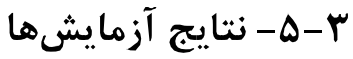

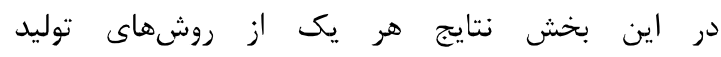

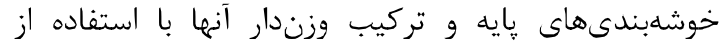

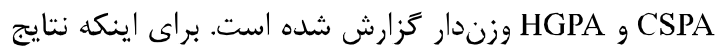

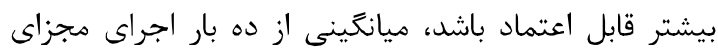

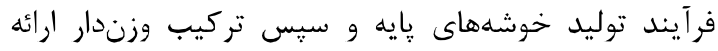
شده است. در نمودارهاى اين بخش خط افتى الئ معيارهاى

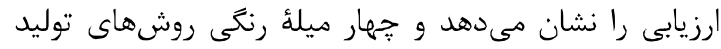

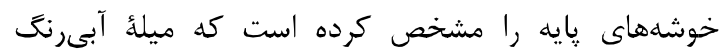

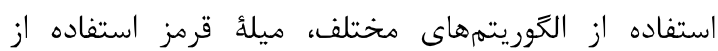

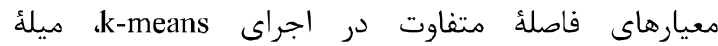

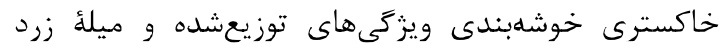
اجراى k-means با kهاى متفاوت است.

هر ميله در نمودار، ميانخين تفاضل CSPA

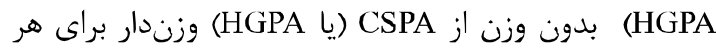
يك از دعيارهاى ارزيابى كزارش شده است. بدينترتيب اعداد مثبت نمايانكر بهبود عملكرد CSPA (يا HGPA) با استفاده

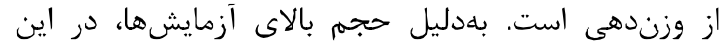

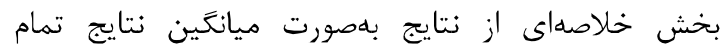
مجموعه دادهها كزارش شده است. تزارش آزمايش تمام

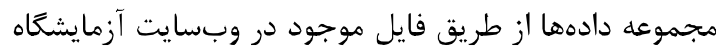
دادهاوى و يادكيرى ماشين دانشگاه قمّ در دسترس است.

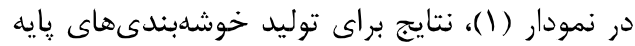
بر مبناى ويزگكىهاى مختلف با استفاده از الكوريتم

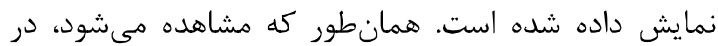

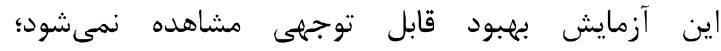

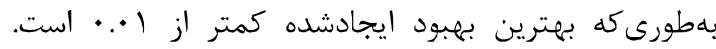

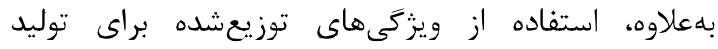
خوشهبندىهاى بايه باعث كاهش دقت در روش CSPA

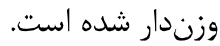

HGPA نمودارهاى (نمودار تا(نمودار تفاضل الكوريته بدون وزن از HGPA وزندار را با وزندهى توسط

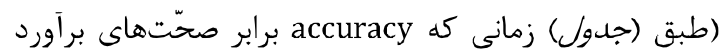
شده توسط AD است نشان مى زدهند.

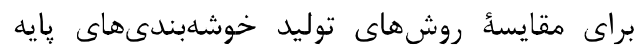
توجه كنيد كه عملكرد روش توليد به روش وزندهائى وابسته است. بهعنوان مثال، روش استفاده از تعداد متفاوت خوشهي تونها

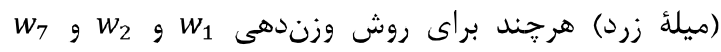

${ }^{3} \mathrm{http}: / / \mathrm{dml} . q o m . a c . i r / w p-$ content/uploads/2017/05/Results_Vahidi.pdf r-ه - معيار هاى ارزيابى نتايج

براى ارزيابى روش بيشنهادى از 9 معيار استفاده شده است.

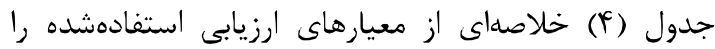

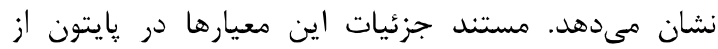
طريق خايكاه scikitlearn قابل دسترسى است. (جدول -r): مجموعه دادههاى مورد آزمايش

(Table-3): Datasets used in the experiments

\begin{tabular}{|c|c|c|c|}
\hline تعداد نمونهها & تعداد ويرگى ها & خوشهها & نام مجموعه \\
\hline 1000 & 8 & 5 & $\begin{array}{c}\text { (دستساز) } \\
\text { 8d5k }\end{array}$ \\
\hline 150 & 4 & 3 & $\begin{array}{c}\text { Iris } \\
\text { (scikitlearn) }\end{array}$ \\
\hline 1797 & 64 & 10 & $\begin{array}{c}\text { Digits } \\
\text { (scikitlearn) }\end{array}$ \\
\hline 210 & 6 & 3 & Seeds (UCI) \\
\hline 258 & 4 & 4 & $\begin{array}{c}\text { Data User } \\
\text { Modeling Int } \\
\text { (UCI) }\end{array}$ \\
\hline 440 & 6 & 3 & $\begin{array}{c}\text { Wholesale } \\
\text { customers data } \\
\text { (LCI) }\end{array}$ \\
\hline 360 & 90 & 15 & $\begin{array}{c}\text { Movement } \\
\text { libras (UCI) }\end{array}$ \\
\hline 110 & 16 & 7 & Zoo (UCI) \\
\hline 178 & 13 & 3 & Wine (UCI) \\
\hline 351 & 34 & 2 & $\begin{array}{c}\text { Ionosphere } \\
\text { (LCI) }\end{array}$ \\
\hline 336 & 7 & 8 & Ecoli (UCl) \\
\hline 210 & 19 & 7 & $\begin{array}{c}\text { Image } \\
\text { segmentation } \\
\text { (UCI) }\end{array}$ \\
\hline 214 & 10 & 7 & Glass (UCI) \\
\hline
\end{tabular}

(جدول - f): معيارهاى ارزيابى روش ضيشنهادى

(Table-4): Evaluation measures

\begin{tabular}{|c|c|c|c|c|}
\hline بُرمال شده & متقارن & بازه ازه & معيار & \\
\hline$\checkmark$ & $\checkmark$ & {$[1,1]$} & \multicolumn{2}{|c|}{ adjusted rand index $(\Lambda \mathrm{RI})$} \\
\hline$\checkmark$ & $x$ & {$[\cdot, 1]$} & \multicolumn{2}{|c|}{ Fowlkes-Mallows (FMI) } \\
\hline$\checkmark$ & $\checkmark$ & $x$ & $\begin{array}{c}\text { اطلاعات متقابل } \\
\text { (MI) }\end{array}$ & \multirow{3}{*}{ متقابل مبتنى برات } \\
\hline$x$ & $\checkmark$ & $\operatorname{Max}=1$ & تطبيق داده شده & \\
\hline$x$ & $\checkmark$ & {$[\cdot, 1]$} & نُرمال شده (N.MI) & \\
\hline$x$ & $x$ & $|\cdot, 1|$ & \multicolumn{2}{|c|}{ همكونى (Homogeneity) } \\
\hline$x$ & $x$ & {$[\cdot, 1]$} & \multicolumn{2}{|c|}{ جامعيّت (Completeness) } \\
\hline$x$ & $\checkmark$ & $|\cdot, 1|$ & \multicolumn{2}{|c|}{$\mathrm{V}$-measure } \\
\hline$x$ & $x$ & {$[\cdot, 1]$} & \multicolumn{2}{|c|}{ خلوص (Purity) } \\
\hline
\end{tabular}

${ }^{1} \mathrm{http}: / /$ scikit-

learn.org/stable/modules/clustering.html\#clusteringperformance-evaluation

${ }^{2} \mathrm{http}: / / \mathrm{nlp}$.stanford.cdu/IR-

book/html/htmledition/evaluation-of-clustering-1.html 
(نمودار - ()): تفاضل الكوريتم CSPA بدون وزن از CSPA وزندار با

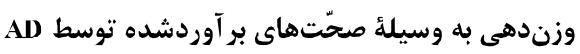

(Chart-1): Subtraction of unweighted CSPA from weighted

CSPA using accuracies estimated by AD method

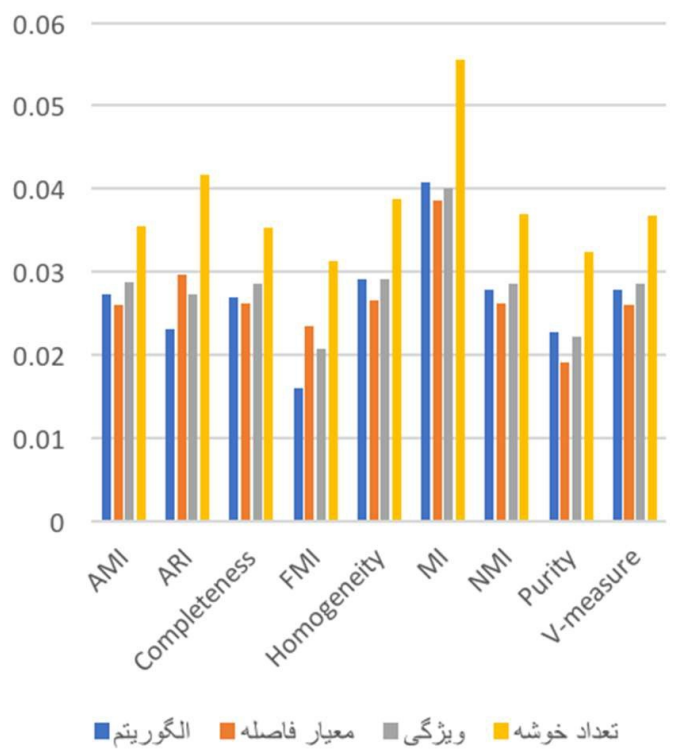

(نمودار - Y): تفاضل الكوريتم HGPA بدون وزن از HGPA وزندار

با وزندهى توسط w 1 و صحّت (Chart-2): Subtraction of HGPA from weighted HGPA by using $w_{1}$ and $\mathrm{AD}$ estimated

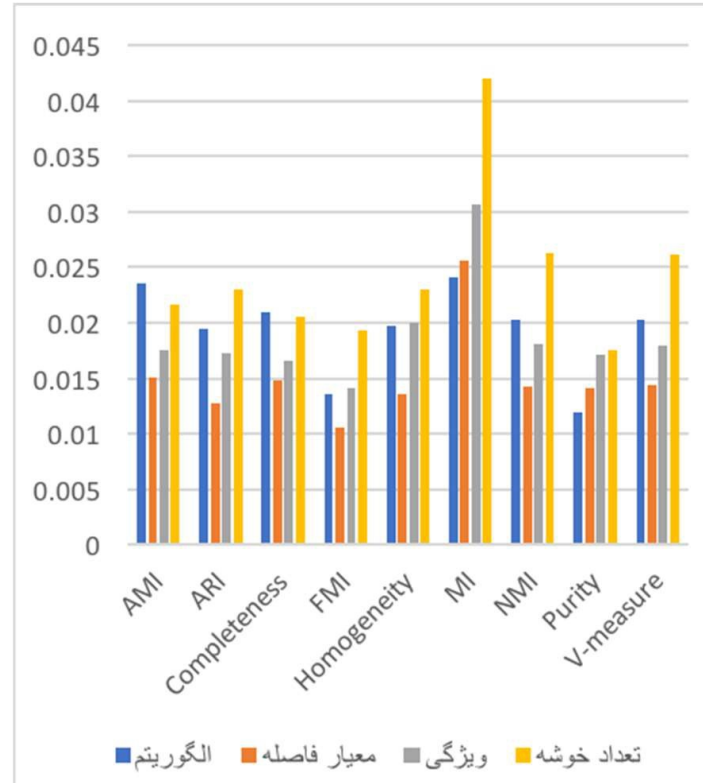

(نمودار - r): تفاضل الكوريتم HGPA بدون وزن از HGPA وزندار

با وزندهى توسط w $w_{2}$ و صحّت هاى بر آوردشده توسط

(Chart-3): Subtraction of HGPA from weighted HGPA by using $w_{2}$ and $\mathrm{AD}$ estimated accuracies
بهترين نتايج را حاصل كرده است، براى روشهاى $w_{3} w_{3}$ و ضعيفتر از بقيئ روشها عمل كرده است. بله همين صورت، رهات روش استفاده از الكوريتمهاى مختلف (ميله آبى) براى روش

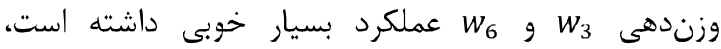
درحالى كه در روش W5 باعث كاهش دقت روش تجميعى

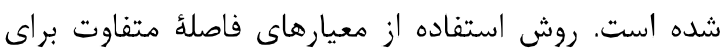
توليد خوشهبندى هاى يايه نيز در روش وزندهى نتايج را بهدست آورده است؛ درنهايت روش ويثز شده كه در بسيارى از روشهاى وزندهى عملكرد قابل

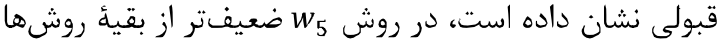
عمل كرده و باعث كاهش دقت الگوريتم تر كيب شده است.

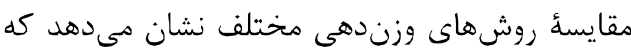

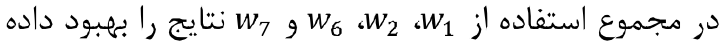
است و بهطور متوسط بهترين نتايج مربوط به زمانى است كه

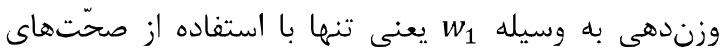

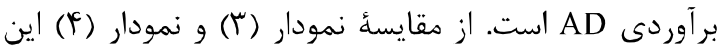
نتيجه حاصل مىشود كه نرمالسازى كارايى را كاهش داده است. نمودار (ع) نيز نشان مىدهد استفاده از نيز كارايى يايينى دارد. در نمودار (ه) ضعيفترين عملكرد مشاهده مئشود

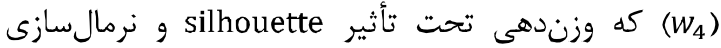
است و AD در آن تأثيرى ندارد. درحالى كه در ديخر وزندهى ها كه AD حضور داشته است، دستكم براى دو مورد از جههار روش توليد خوشهبندىهاى يايه بهبود مشاهده مىشود كه نشاندهندة مؤثربون روش ارائهشده در اين

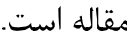

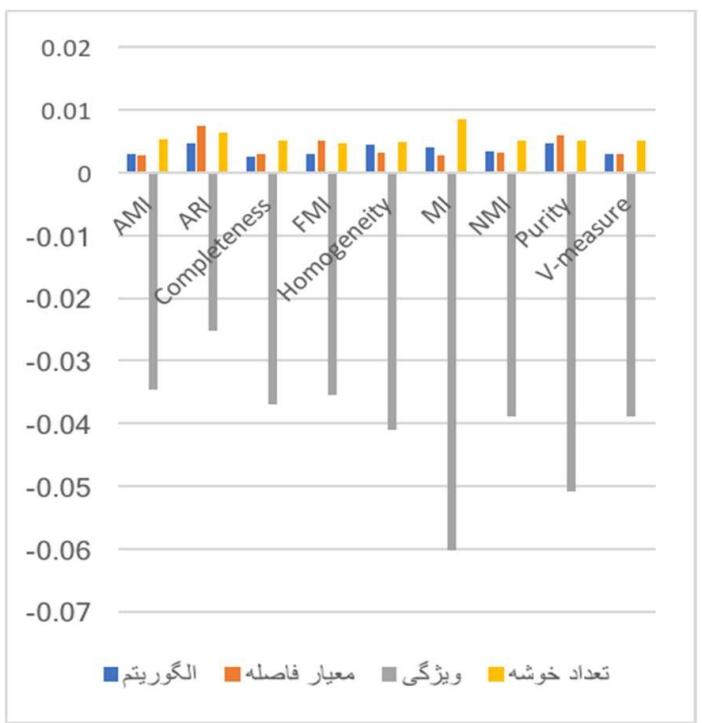




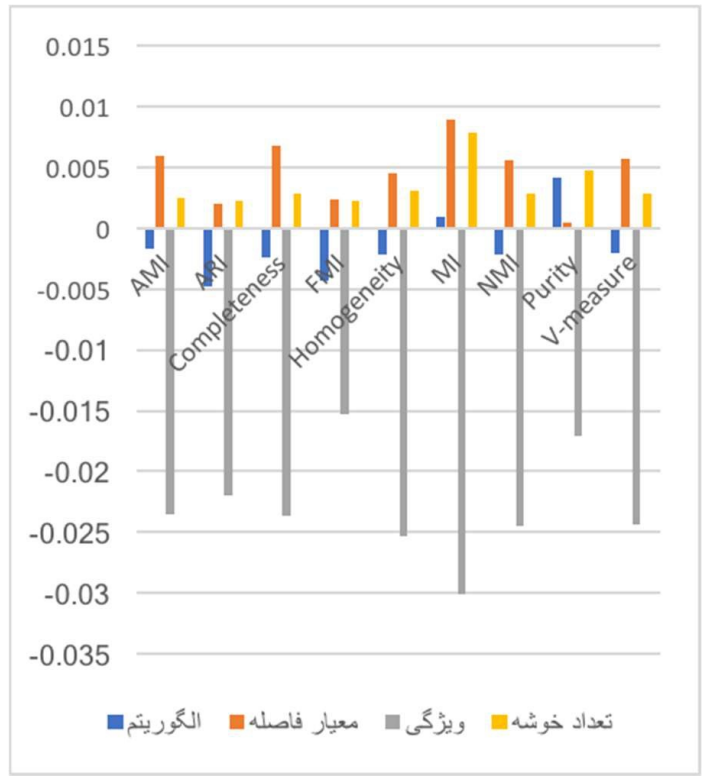

(نمودار - \&): تفاضل الكوريتم HGPA بدون وزن از HGPA وزن دار

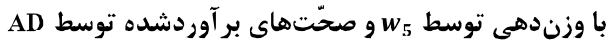

(Chart-6): Subtraction of HGPA from weighted HGPA by using $w_{5}$ and $\mathrm{AD}$ estimated accuracies

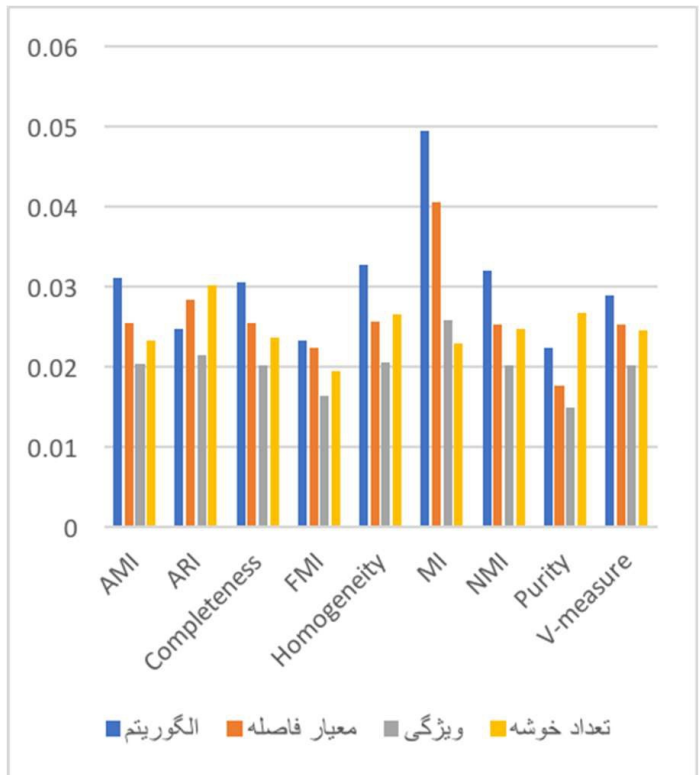

(نمودار -Y): تفاضل الكوريتم HGPA بدون وزن از HGPA وزن ودار

با وزندهى توسط w $w_{6}$ و صحّت هاى بر آوردشده توسط (Chart-7): Subtraction of HGPA from weighted HGPA by using $w_{6}$ and $\mathrm{AD}$ estimated accuracies

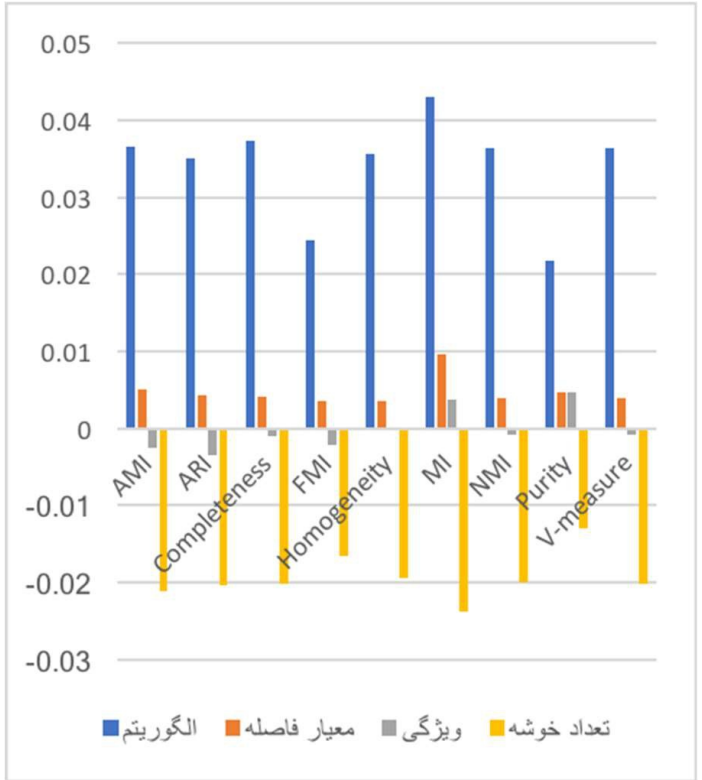

(نمودار - F): تفاضل الكوريتم HGPA بدون وزن از HGPA وزن دار

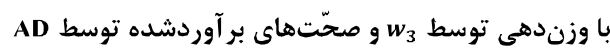
(Chart-4): Subtraction of HGPA from weighted HGPA by using $w_{3}$ and $\mathrm{AD}$ estimated accuracies

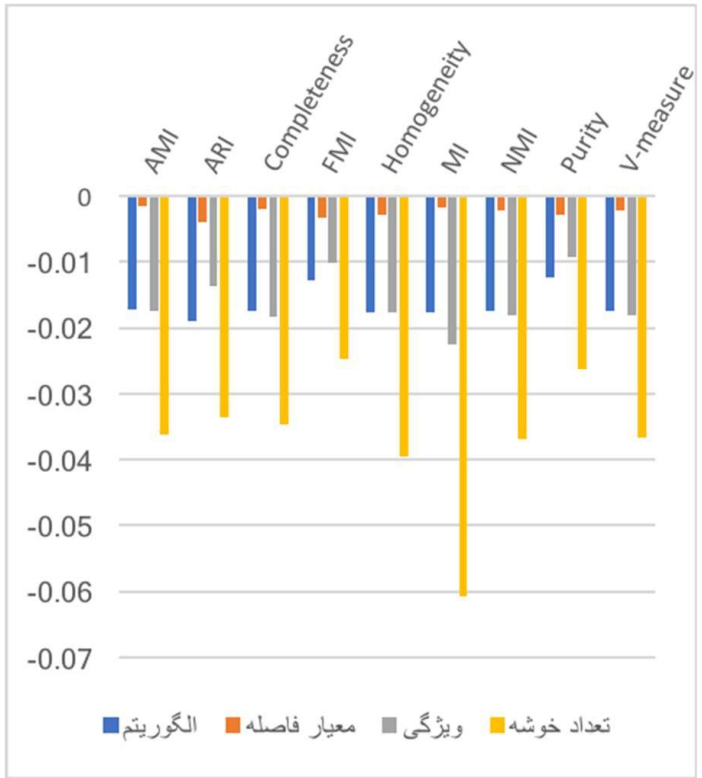

(نمودار -ه)): تفاضل الكوريتم HGPA بدون وزن از HGPA وزنددار

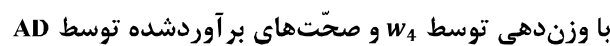

(Chart-5): Subtraction of HGPA from weighted HGPA by using $w_{4}$ and AD estimated accuracies 
با توجه باه بهبود صحّت خوشهبندى نهايى با وزندهى

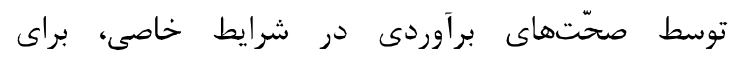

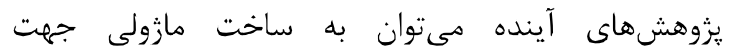

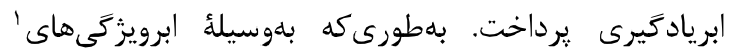

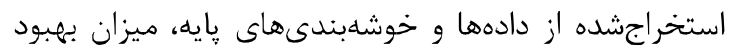
خوشابندى نهايى را ييشبينى كند. براى اين منظور بايد روى مجموعه دادهاى بيشترى آزمايش صورت بخيرد تا

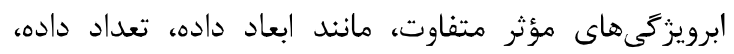

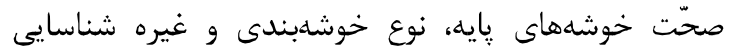

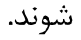

\section{7- References}

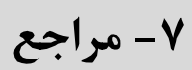

[1] J. Han, M. Kamber, and J. Pei, Data mining: concepts and techniques. Elsevier, 2011.

[2] S. Vega-Pons and J. Ruiz-Shulcloper, "a Survey of Clustering Ensemble Algorithms," Int. J. Pattern Recognit. Artif. Intell., vol. 25, no. 03, pp. 337-372, 2011.

[3] J. Kittler, M. Hatef, R. P. W. Duin, and J. Matas, "On combining classifiers," IEEE Trans. Pattern Anal. Mach. Intell., vol. 20, no. 3, pp. 226-239, 1998.

[4] S.-B. Cho and J. H. Kim, "Combining multiple neural networks by fuzzy integral for robust classification," Syst. Man Cybern. IEEE Trans., vol. 25, no. 2, pp. 380-384, 1995.

[5] J. Franke and E. Mandler, "A comparison of two approaches for combining the votes of cooperating classifiers," in Pattern Recognition, 1992. Vol. II. Conference B: Pattern Recognition Methodology and Systems, Proceedings., 11th IAPR International Conference on, 1992, pp. 611-614.

[6] L. K. Hansen and P. Salamon, "Neural network ensembles," IEEE Trans. Pattern Anal. Mach. Intell., no. 10, pp. 993-1001, 1990.

[7] S. Hashem and B. Schmeiser, "Improving model accuracy using optimal linear combinations of trained ncural networks," Neural Networks, IEEE Trans., vol. 6, no. 3, pp. 792-794, 1995.

[8] J. Kittler, "Improving recognition rates by classificr combination: A theoretical framework," DAC and IS, editors, Progress in Handwriting Recognition, pp. 231-248, 1997.

[9] D. J. Miller and L. Yan, "Critic-driven ensemble classification," Signal Process. IEEE Trans., vol. 47, no. 10, pp. 2833-2844, 1999.

${ }^{1}$ meta-feature

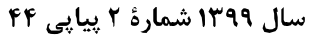

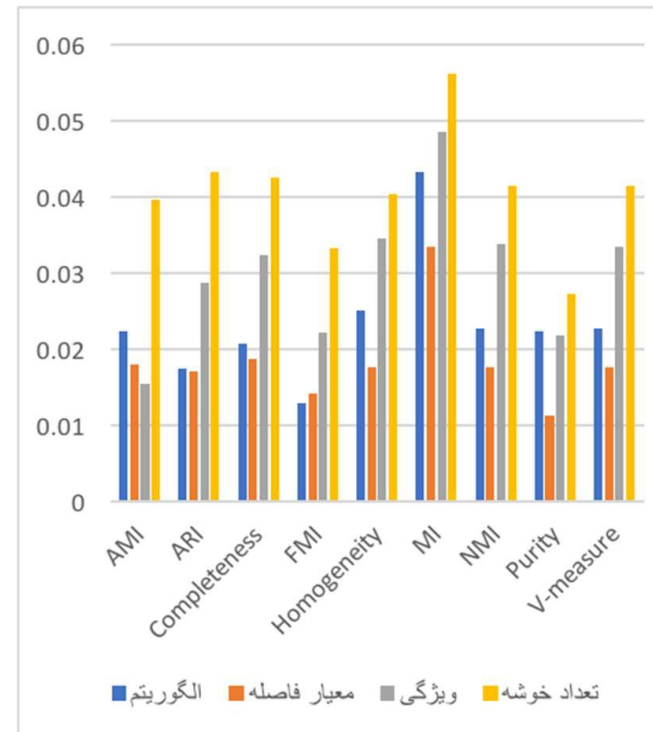

(نمودار -1): تفاضل الكوريته HGPA بلون وزن از HGPA وزندار

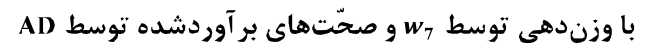

(Chart-8): Subtraction of HGPA from weighted HGPA by using $w_{7}$ and AD estimated accuracies

\section{9- نتيجه}

در اين مقاله روشى براى تركيب خوشهبندىهاى بايه با

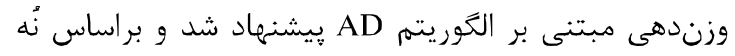

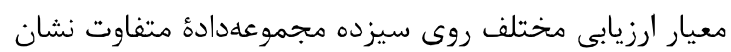

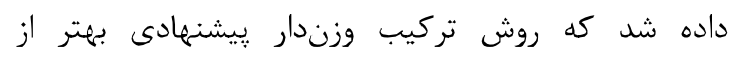

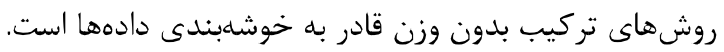

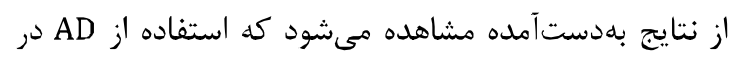

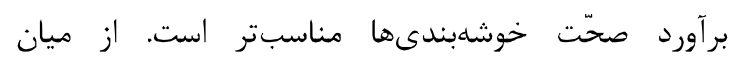
روشهاى وزندهى مختلفى كه براى ابريالها بيشنهاد شادئ

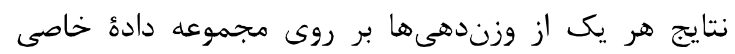

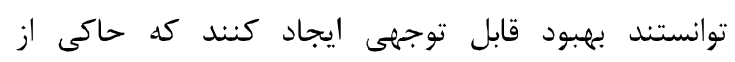

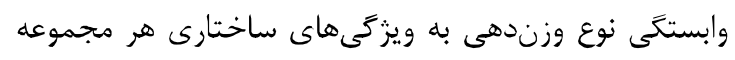

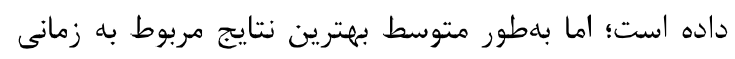

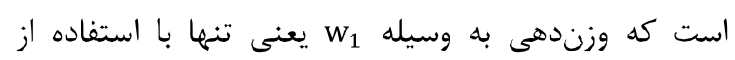

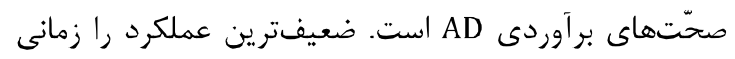

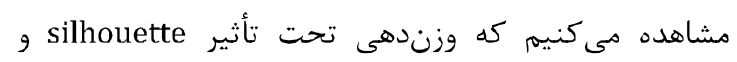
نرمالسازى مىباشد و AD در آن تأثيرى ندارد.

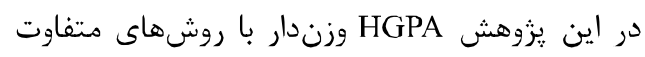
توليد خوشههاى بايه مورد بررسى قرار كرفت. نتايج آزمايش

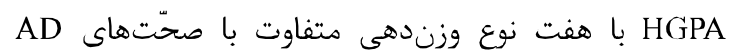

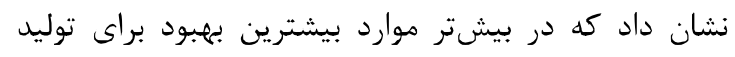

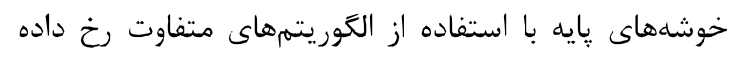


international conference on Knowledge discovery in data mining, 2005, pp. 70-77.

[24] A. Topchy, A. K. Jain, and W. Punch, "Combining multiple weak clusterings," in Data Mining, 2003. ICDM 2003. Third IEEE International Conference on, 2003, pp. 331338.

[25] L. I. Kuncheva, S. T. Hadjitodorov, and Others, "Using diversity in cluster ensembles," in Systems, man and cybernetics, 2004 IEEE international conference on, 2004, vol. 2, pp. 1214-1219.

[26] B. Minaei-Bidgoli, A. Topchy, and W. F. Punch, "Ensembles of partitions via data resampling," in Information Technology: Coding and Computing, 2004. Proceedings. ITCC 2004. International Conference on, 2004, vol. 2, pp. $188-192$.

[27] A. Topchy, A. K. Jain, and W. Punch, "Clustering ensembles: Models of consensus and weak partitions," Pattern Anal. Mach. Intell. IEEE Trans., vol. 27, no. 12, pp. 1866-1881, 2005.

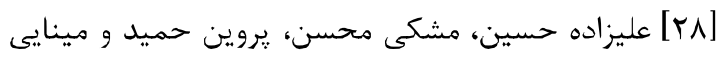

$$
\begin{aligned}
& \text { بيد }
\end{aligned}
$$

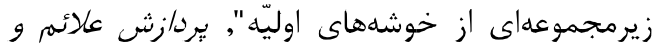

$$
\begin{aligned}
& \text { د/50)، }
\end{aligned}
$$

[28] H. Alizadeh, M. Moshki, H. Parvin, B. Minaei Bidgoli, "Clustering ensemble based on combination of subset of primary clusters," Signal and Data Processing, vol. 7, no. 1, pp. 19-32, 2010.

[29] L. Franek and X. Jiang, "Ensemble clustering by means of clustering cmbedding in vector spaces," Pattern Recognit., vol. 47, no. 2, pp. 833-842, 2014.

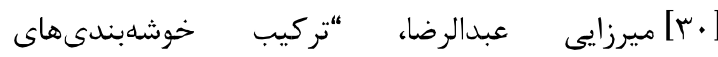

$$
\begin{aligned}
& \text { سلسلهمراتبى با تأكيد بر حفظ اطلاعات ساختارى }
\end{aligned}
$$

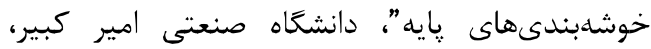

$$
\begin{aligned}
& .1 T \wedge \Lambda
\end{aligned}
$$

[30] A. Mirzaei, "Combining hierarchical clusterings with emphasis on retaining the structural contents of the base clusterings," $P h D$ dissertation, Amirkabir University of Technology, 2009.

[31] J. H. Friedman and J. J. Meulman, "Clustering objects on subsets of attributes," J. R. Stat. Soc. Ser. B (Statistical Methodol.), vol. 66, no. 4, pp. 815-849, 2004.

[32] C. Domeniconi, D. Gunopulos, S. Ma, B. Yan, M. Al-Razgan, and D. Papadopoulos, "Locally adaptive metrics for clustering high dimensional
[10] K. W. De Bock, K. Coussement, and D. Van den Pocl, "Enscmble classification based on generalized additive models," Comput. Stat. Data Anal., vol. 54, no. 6, pp. 1535-1546, 2010.

[11] C. Domeniconi and M. Al-Razgan, "Weighted cluster ensembles: Methods and analysis," $A C M$ Trans. Knowl. Discov. from Data, vol. 2, no. 4, pp. 17, 2009.

[12] A. Strehl and J. Ghosh, "Cluster ensembles---a knowledge reusc framework for combining multiple partitions," J. Mach. Learn. Res., vol. 3, no. Dec, pp. 583-617, 2002.

[13] H. Amirkhani and M. Rahmati, "Agreement/disagreement based crowd labeling," Appl. Intell., vol. 41, no. 1, pp. 212222, Jul. 2014.

[14] N. Littlestone and M. K. Warmuth, "The weighted majority algorithm," in Foundations of Computer Science, 1989., 30th Annual Symposium on, 1989, pp. 256-261.

[15] S. B. Kotsiantis, I. Zaharakis, and P. Pintelas, "Supervised machine learning: A review of classification techniques." Emerging Artificial Intelligence Applications in Computer Engineering, vol. 160, pp. 3-24, 2007.

[16] T. G. Dietterich, "Ensemble methods in machine learning," in International workshop on multiple classifier systems, 2000, pp. 1-15.

[17] T. Windeatt, "Vote counting measures for ensemble classifiers," Pattern Recognit., vol. 36, no. 12, pp. 2743-2756, 2003.

[18] S. Wang, A. Mathew, Y. Chen, L. Xi, L. Ma, and J. Lee, "Empirical analysis of support vector machine ensemble classifiers," Expert Syst. Appl., vol. 36, no. 3, pp. 6466-6476, 2009.

[19] A. J. C. Sharkey, Combining artificial neural nets: ensemble and modular multi-net systems. Springer Science \& Business Media, 2012.

[20] A. L. N. Fred and A. K. Jain, "Data clustering using evidence accumulation," in Pattern Recognition, 2002. Proceedings. 16th International Conference on, 2002, vol. 4, pp. 276-280.

[21] A. Topchy, A. K. Jain, and W. Punch, "A mixture model for clustering ensembles," in Society for Industrial and Applied Mathematics. Proceedings of the SIAM International Conference on Data Mining, 2004, pp. 379.

[22] S. Dudoit and J. Fridlyand, "Bagging to improve the accuracy of a clustering procedure," Bioinformatics, vol. 19, no. 9, pp. 1090-1099, 2003.

[23] D. Gondek and T. Hofmann, "Non-redundant clustering with conditional ensembles," in Proceedings of the eleventh ACM SIGKDD 
[43] A. Litifi Pakdehi, N. Daneshpour, "Cluster ensemble selection using voting," Signal and Data Processing, vol. 15, no. 4, pp. 17-30, 2019.

[44] Z. Yu and H. S. Wong, "Class discovery from gene expression data based on perturbation and cluster ensemble," IEEE Trans. Nanobioscience, vol. 8, no. 2, pp. 147-160, 2009.

[45] H. Liu, M. Shao, S. Li, and Y. Fu, "Infinite enscmble clustering," Data Min. Knowl. Discov., vol. 32, no. 2, pp. 385-416, 2018.

[46] D. Huang, C.-D. Wang, and J.-H. Lai, "Locally weighted ensemble clustering," IEEE Trans. Cybern., vol. 48, no. 5, pp. 1460-1473, 2018.

[47] C. Zhong, L. Hu, X. Yue, T. Luo, Q. Fu, and H. $\mathrm{Xu}$, "Ensemble clustering based on evidence extracted from the co-association matrix," Pattern Recognit., vol. 92, pp. 93-106, 2019.

[48] F. Li, Y. Qian, J. Wang, C. Dang, and L. Jing, "Clustering ensemble based on sample's stability," Artif. Intell., vol. 273, pp. 37-55, 2019.

[49] G. Karypis and V. Kumar, "A fast and high quality multilevel scheme for partitioning irregular graphs," SIAM J. Sci. Comput., vol. 20, no. 1, pp. 359-392, 1998.

[50] G. Karypis, R. Aggarwal, V. Kumar, and S. Shekhar, "Multilevel hypergraph partitioning: applications in VLSI domain," IEEE Trans. Very Large Scale Integr. Syst., vol. 7, no. 1, pp. 69-79, 1999.

[51] L. Rokach and O. Maimon, "Clustering methods," in Data mining and knowledge discovery handbook, Springer, 2005, pp. 321352.

[52] P. J. Rousseeuw, "Silhouettes: a graphical aid to the interpretation and validation of cluster analysis," J. Comput. Appl. Math., vol. 20, pp. 53-65, 1987.
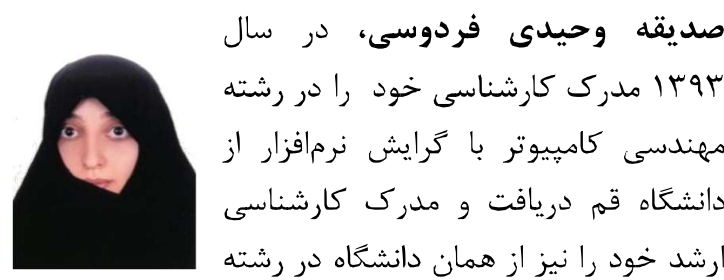

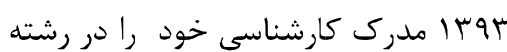
مهندسى كامييوتر با كرايش نرمافزار از

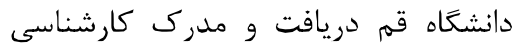
ارشد خود را نيز از همان دانشعاه در رشته مهندسى فناورى اطلاعات با گرايش تجارت الكترونيك در سال هوبا اخذ كرد. موضوع קياياننامه كارشناسى ارشد ايشان تركيب وزندار خوشابندىها با هدف افزايش دقت خوشهبندى نهايى بوده است. زمينههاى يزوهشى مورد علاقه وى يادكيرى ماشين و دادهكاوى است. نشانى رايانامه ايشان عبارت است ازئ واده s.vahidi@stu.qom.ac.ir data," Data Min. Knowl. Discov., vol. 14, no. 1, pp. 63-97, 2007.

[33] M. Al-Razgan and C. Domeniconi, "Weighted clustering ensembles," in Proceedings of the 2006 SIAM International Conference on Data Mining, 2006, pp. 258-269.

[34] S. Vega-Pons, J. Correa-Morris, and J. RuizShulcloper, "Weighted cluster ensemble using a kernel consensus function," in Iberoamerican Congress on Pattern Recognition, 2008, pp. 195-202.

[35] S. Vega-Pons and J. Ruiz-Shulcloper, "Clustering ensemble method for heterogeneous partitions," in Iberoamerican Congress on Pattern Recognition, 2009, pp. 481-488.

[36] T. Li and C. Ding, "Weighted consensus clustering," in Proceedings of the 2008 SIAM International Conference on Data Mining, 2008, pp. 798-809.

[37] F. Gullo, A. Tagarelli, and S. Greco, "DiversityBased Weighting Schemes for Clustering Enscmbles," in Proceedings of the 2009 SIAM International Conference on Data Mining, 2009, pp. 437-448.

[38] J. W. C.-D. Huang Dong; Lai, "Ensemble clustering using factor graph," Pattern Recognit., vol. 50, pp. 131-142, 2015.

[39] H. Liu, J. Wu, T. Liu, D. Tao, and Y. Fu, "Spectral Ensemble Clustering via Weighted KMeans: Theoretical and Practical Evidence," IEEE Trans. Knowl. Data Eng., vol. 29, no. 5, pp. 1129-1143, 2017.

[40] Y. Ren, C. Domeniconi, G. Zhang, and G. Yu, "Weighted-object ensemble clustering: methods and analysis," Knowl. Inf. Syst., pp. 1-29, 2016.

[41] Q. Kang, S. Liu, M. Zhou, and S. Li, "A weightincorporated similarity-based clustering ensemble method based on swarm intelligence," Knowledge-Based Syst., vol. 104, pp. 156-164, 2016.

$$
\begin{aligned}
& \text { [FY] يروين حميد، “خوشه بندى تركيبى با وزن دهى توام }
\end{aligned}
$$

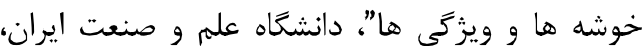

$$
\begin{aligned}
& \text {. }
\end{aligned}
$$

[42] H. Parvin, " Clustering ensembles with weighting clusters and features," PhD dissertation, Iran University of Science \& Technology, 2013.

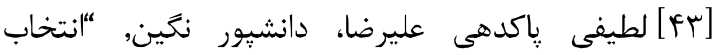

$$
\begin{aligned}
& \text { اعضاى تركيب در خوشهبندى تركيبى با استفاده از }
\end{aligned}
$$

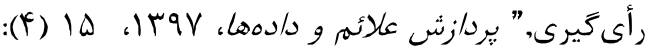



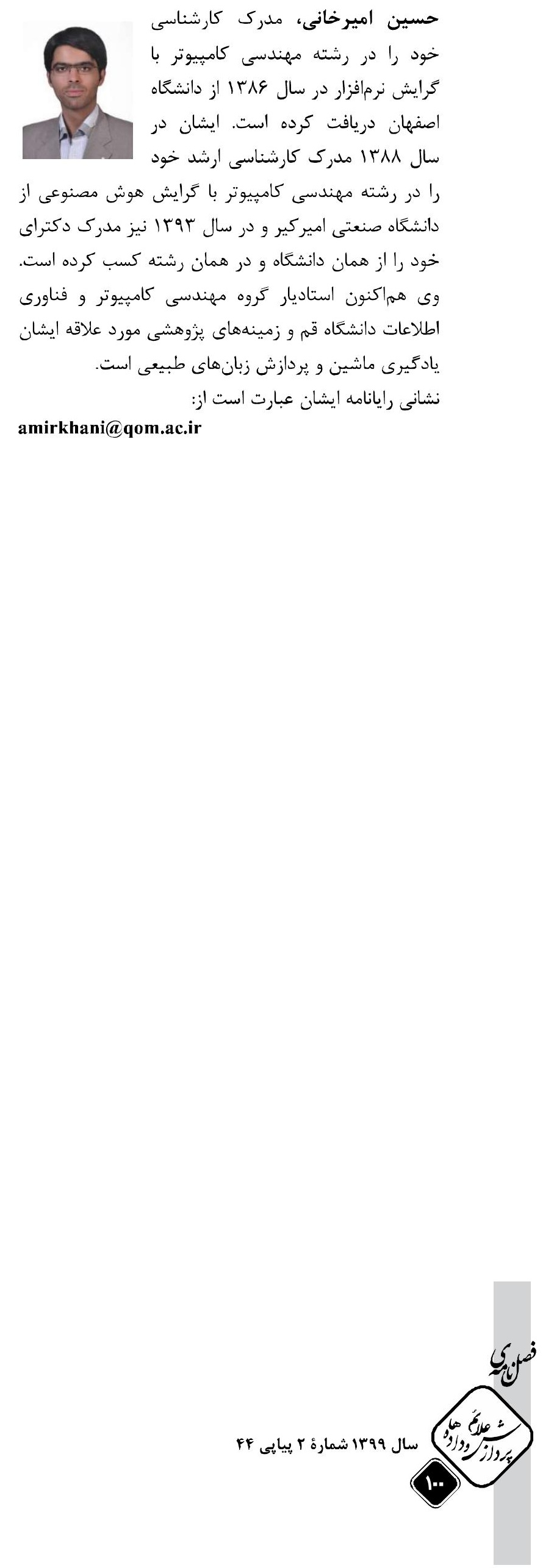